\title{
The Effects of Enhanced Sea Ice Export from the Ross Sea on Recent Cooling and Freshening of the Southeast Pacific ${ }^{\mathscr{O}}$
}

\author{
IVANA CEROVEČKI \\ Scripps Institution of Oceanography, La Jolla, California \\ ANDREW J. S. MEIJERS \\ British Antarctic Survey, Cambridge, United Kingdom \\ Matthew R. Mazloff, SARAh T. Gille, and Veronica M. TAMsitT ${ }^{a}$ \\ Scripps Institution of Oceanography, La Jolla, California \\ PAUl R. HOLland \\ British Antarctic Survey, Cambridge, United Kingdom
}

(Manuscript received 10 April 2018, in final form 12 January 2019)

\begin{abstract}
The top $2000 \mathrm{~m}$ of the Southern Ocean has freshened and warmed over recent decades. However, the highlatitude (south of $50^{\circ} \mathrm{S}$ ) southeast Pacific was observed to be cooler and fresher in the years 2008-10 compared to 2005-07 over a wide depth range including surface, mode, and intermediate waters. The causes and impacts of this event are analyzed using the ocean-sea ice data-assimilating Southern Ocean State Estimate (SOSE) and observationally based products. In 2008-10, a strong positive southern annular mode coincided with a negative El NiñoSouthern Oscillation and a deep Amundsen Sea low. Enhanced meridional winds drove strong sea ice export from the eastern Ross Sea, bringing large amounts of ice to the Amundsen Sea ice edge. In 2008, together with increased precipitation, this introduced a strong freshwater anomaly that was advected eastward by the Antarctic Circumpolar Current (ACC), mixing along the way. This anomaly entered the ocean interior not only as Antarctic Intermediate Water, but also as lighter Southeast Pacific Subantarctic Mode Water (SEPSAMW). A numerical particle release experiment carried out in SOSE showed that the Ross Sea sector was the dominant source of particles reaching the SEPSAMW formation region. This suggests that large-scale climate fluctuations can induce strong interannual variability of volume and properties of SEPSAMW. These fluctuations act at different time scales: instantaneously via direct forcing and also lagged over advective time scales of several years from upstream regions.
\end{abstract}

\section{Introduction}

The top $2000 \mathrm{~m}$ of the extratropical Southern Ocean has freshened (e.g., Wong et al. 1999; Aoki et al. 2005; Durack et al. 2012) and warmed (e.g., Gille 2008,

Supplemental information related to this paper is available at the Journals Online website: https://doi.org/10.1175/JCLI-D-18-0205.s1.

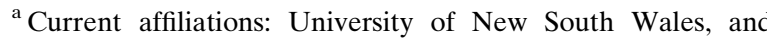
Australia University of New South Wales, and Centre for Southern Hemisphere Oceans Research (CSHOR), CSIRO Oceans and Atmosphere, Hobart, Tasmania, Australia.
}

Corresponding author: Ivana Cerovečki, icerovecki@ucsd.edu
Meijers et al. 2011) over recent decades. Southern Ocean freshening has been variously attributed to changes in precipitation (Wong et al. 1999; Durack et al. 2012; Swart et al. 2018) or to changes in glacial melt (Jacobs et al. 2002; Jacobs and Giulivi 2010; Purkey and Johnson 2013; Paolo et al. 2015). Haumann et al. (2016) have attributed the freshening observed over the last several decades to an increase in wind-driven northward freshwater transport by Antarctic sea ice. This increase was strongest and most robust in the Pacific sector of the Southern Ocean. In this sector, freshening was caused by increased southerly winds over the Ross Sea region, enhancing northward sea ice advection since the early 1990s (Haumann et al. 2014; Holland and Kwok 2012). Strengthening of southerly winds over the Ross Sea is 
associated with a trend toward a zonally more asymmetric distribution of atmospheric pressure in the Southern Ocean (Carril and Navarra 2001; Landschützer et al. 2015). A key component of the nonzonal distribution of atmospheric pressure in the Southern Ocean is the Amundsen Sea low (ASL; Raphael et al. 2016). The ASL is a climatological area of low pressure in the high-latitude $\left(60^{\circ}-70^{\circ} \mathrm{S}\right)$ South Pacific sector of the Southern Ocean, which comprises the Ross Sea, the Amundsen Sea, and the Bellingshausen Sea (Raphael et al. 2016). The ASL significantly influences the formation and properties of two major water masses in the southeast Pacific: Southeast Pacific Subantarctic Mode Water (SEPSAMW) and Antarctic Intermediate Water (AAIW) (Close et al. 2013, hereafter C13).

Subantarctic Mode Waters (SAMWs) are produced in several locations in the Indian and Pacific Oceans when the upper-ocean mixed layer deepens in winter (e.g., Aoki et al. 2007; McCartney 1982). They are characterized by low potential vorticity (PV) with properties that are vertically nearly uniform over several hundred meters (Hanawa and Talley 2001). PV is defined here as $\mathrm{PV}=\left(f / \rho_{0}\right) \partial \sigma_{\theta} / \partial z$, where $f$ is the Coriolis parameter, $\rho_{0}$ is the reference density of seawater, and $\sigma_{\theta}$ is the potential density (taken here to be defined relative to the surface). AAIW is the salinity minimum layer found north of the Polar Front, below the SAMW. Mechanisms of AAIW renewal are still under debate. McCartney $(1977,1982)$ suggested that AAIW forms primarily in the southeast Pacific, where the coldest and freshest variety of SAMW is transformed into AAIW. Molinelli (1981) suggested that AAIW is formed by isopycnal processes within the Antarctic Circumpolar Current (ACC) latitude range, while Sloyan and Rintoul (2001) emphasized the importance of diapycnal exchange.

Analyzing Argo data, Roemmich et al. (2015) showed that over the 2006-13 time period the high-latitude southeast Pacific (south of $50^{\circ} \mathrm{S}$, approximately between $160^{\circ} \mathrm{W}$ and Drake Passage) cooled (their Fig. 3). This cooling is counter to the dominant warming signal found in the extratropical Southern Hemisphere over the last decade (Desbruyères et al. 2016). The cooling region encompasses the formation regions of both SEPSAMW and AAIW, which subduct within and just equatorward of the ACC. Subsequently SEPSAMW and AAIW are exported northward, thus bringing newly ventilated water to large areas of the lower thermocline in all Southern Hemisphere subtropical oceans (Schmitz 1996; Hanawa and Talley 2001; Herraiz-Borreguero and Rintoul 2011; Jones et al. 2016). Therefore, changes in the temperature and salinity of SEPSAMW and AAIW have the potential to modify surface uptake, storage, and transport out of the Southern Ocean of freshwater, heat, carbon (Sabine et al. 2004; Ito et al. 2010), chlorofluorocarbons (Willey et al. 2004; Hartin et al. 2011), and nutrients (Sarmiento et al. 2004). Strong interannual and interdecadal variability of volume and thermohaline properties of SEPSAMW and AAIW is primarily controlled by variability in the atmospheric circulation associated with changes in the ASL (C13; Naveira Garabato et al. 2009, hereafter NG09).

Changes in the depth of the ASL are related to global and hemispheric modes of climate variability, so that the central pressure of the ASL is significantly lower during the La Niña phase of El Niño-Southern Oscillation (-ENSO), compared to the El Niño phase (+ENSO), and during the positive southern annular mode (+SAM) phase (Raphael et al. 2016). During the years considered here (2005-10), two time periods can be distinguished, defined by the relative phases of SAM and ENSO. In the early Argo years, from 2005 until late 2007, SAM and ENSO were in phase (Fig. 1a). Thereafter, from 2008 to 2010, SAM and ENSO were out of phase, and strong +SAM coincided with - ENSO (Fig. 1a), while the ASL was anomalously low and located further east of its mean location (Figs. 1b and 2).

The objective of this study is to analyze changes in the high-latitude southeast Pacific during the time period 2005-10, concentrating on the transition from conditions associated with in-phase + SAM and +ENSO with weak ASL (2005-07), to conditions associated with strong outof-phase +SAM and -ENSO, with anomalously deep ASL (2008-10). We analyze changes in volume and properties of SEPSAMW, which are tightly coupled to atmospheric and cryospheric forcings, and seek to identify mechanisms causing the observed changes between the time periods 2005-07 and 2008-10. The motivation came from NG09's analysis of observations from the Drake Passage for the years 1969-2005. NG09 showed that in 1998 there was a prominent exception to the prevailing modes of SAMW and AAIW formation, driven predominantly by air-sea buoyancy fluxes. Instead, a strong wind forcing associated with constructive interference between -ENSO and a very strong +SAM caused a transitory shift to an Ekmandominated mode of SAMW formation and a 1-2-yr shutdown of AAIW production. In 1998-99 two modes of SAMW were observed in the southeast Pacific: a volumetrically dominant cold and fresh southern mode and a warm and salty northern mode (NG09). SAM has a very strong influence on SAMW distribution in the South Pacific, especially in its central part $\left(90^{\circ}-160^{\circ} \mathrm{W}\right)$, where deepening of winter mixed layers under + SAM conditions can be on the order of $100 \mathrm{~m}$, while changes in southeast Pacific are much smaller (Sallée et al. 2010a). 

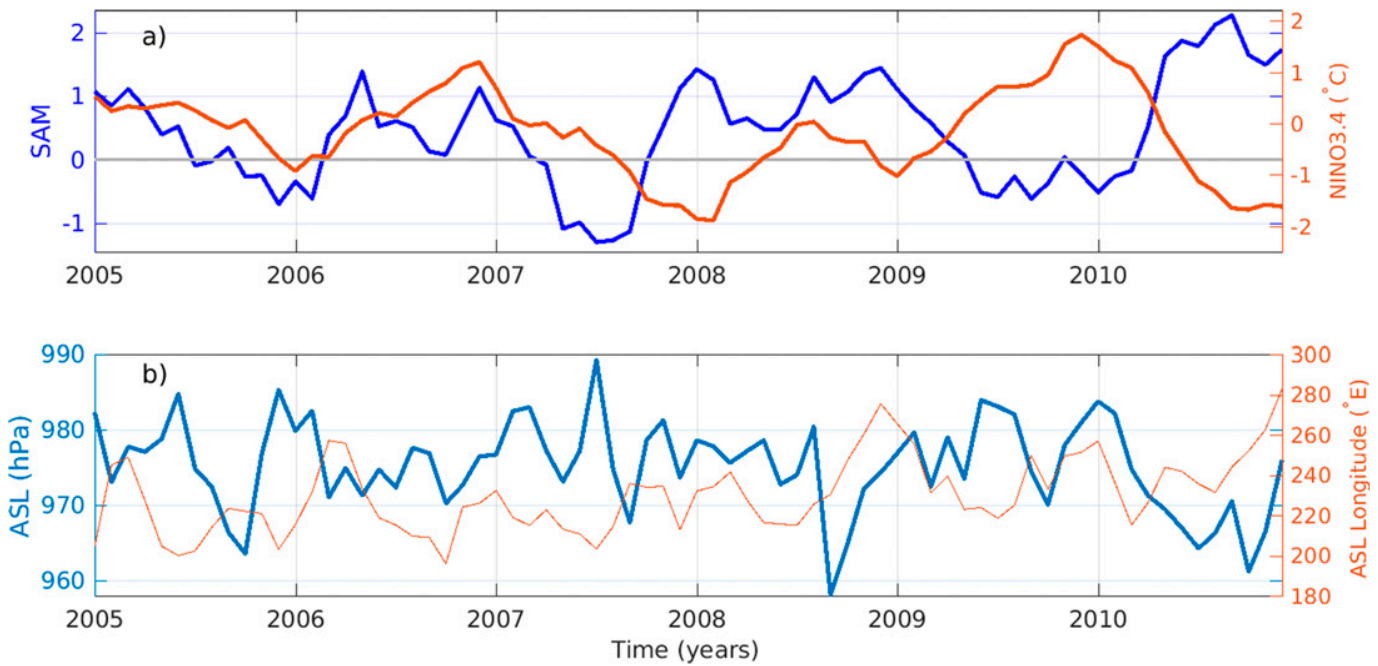

FIG. 1. For 2005-10: (a) Niño-3.4 SST anomaly $\left({ }^{\circ} \mathrm{C}\right.$; red; http://www.cpc.ncep.noaa.gov/data/indices/sstoi.indices), and 5-month running mean of the Marshall SAM index (Marshall 2003; Marshall et al. 2018; blue) and (b) the monthly mean of ASL central pressure (hPa) obtained from the ASL Index version 2 (Hosking et al. 2016), based on ERA-Interim Reanalysis data, (blue; data from https://legacy.bas.ac.uk/data/absl/ASL-index-Version2Monthly-ERA-Interim_Hosking2016.txt) and the 3-month running mean of east longitude $\left(^{\circ}\right)$ of the ASL central low pressure (orange).

We focus on the years $2005-10$ because for this time period, besides the Argo product of Roemmich and Gilson (2009) (hereafter the "RG09 Argo product," subsequently extended to include later years and available online), we also have the results of the Southern Ocean State Estimate (SOSE), a data-assimilating, eddy-permitting ocean-sea ice coupled model (Mazloff et al. 2010). SOSE is particularly well suited for comparing modeled and observed water mass properties because it is constrained by oceanic observations while also conserving mass and tracer properties. Its large-scale state is consistent with raw Argo observations, with good agreement in the SEPSAMW and AAIW density range (Abernathey et al. 2016). In addition, SOSE sea ice properties agree well with observed sea ice thickness and concentration, suggesting that SOSE can provide an accurate estimate of the freshwater budget (Abernathey et al. 2016), which is otherwise a difficult budget to infer (Dong et al. 2009). The additional advantage of working with SOSE is that all terms in the salinity $S$ equation that SOSE solves are time averaged during the run and archived as 5-day averages, enabling us to close the $S$ budget.

This paper is organized as follows. A description of the tools, methods, and SAMW volume and properties in the southeast Pacific in 2005-10 is given in section 2. In section 3, we document the changes in the atmospheric and cryospheric forcings between the time periods $2005-07$ and $2008-10$, and we discuss the resulting changes in oceanic conditions. Causal mechanisms for these changes are addressed using a salt budget analysis for 2008-10 in the region of strongest freshening observed in the high-latitude southeast Pacific. Changes in SEPSAMW between the time periods 2008-10 and 2005-07 are further discussed in section 4. A particle release experiment, presented in section 5, reveals pathways and advective time scales for salinity anomalies to travel between regions of sea ice melt and regions of SEPSAMW formation. Section 6 provides discussion and conclusions.

\section{Tools and methods}

\section{a. Southern Ocean State Estimate}

SOSE is a solution to the MITgcm ocean and sea ice model, developed using the ECCO consortium's assimilation software (Wunsch and Heimbach 2013). It is configured in spherical coordinates, with $1 / 6^{\circ}$ horizontal resolution and 42 depth levels of variable thickness. Although a horizontal resolution of $1 / 6^{\circ}$ is too coarse to resolve the first Rossby deformation radius poleward of the ACC, SOSE spontaneously develops a reasonable mesoscale eddy field. SOSE thus does not use an isopycnal mesoscale eddy mixing parameterization. The diffusivity values instead are given as constants, and we have not attempted to implement an eddy flux parameterization regulated by the deformation radius (e.g., Hallberg 2013).

To bring the forward model solution into consistency with observations, the optimization adjusts the atmospheric variables (air temperature, specific humidity, 

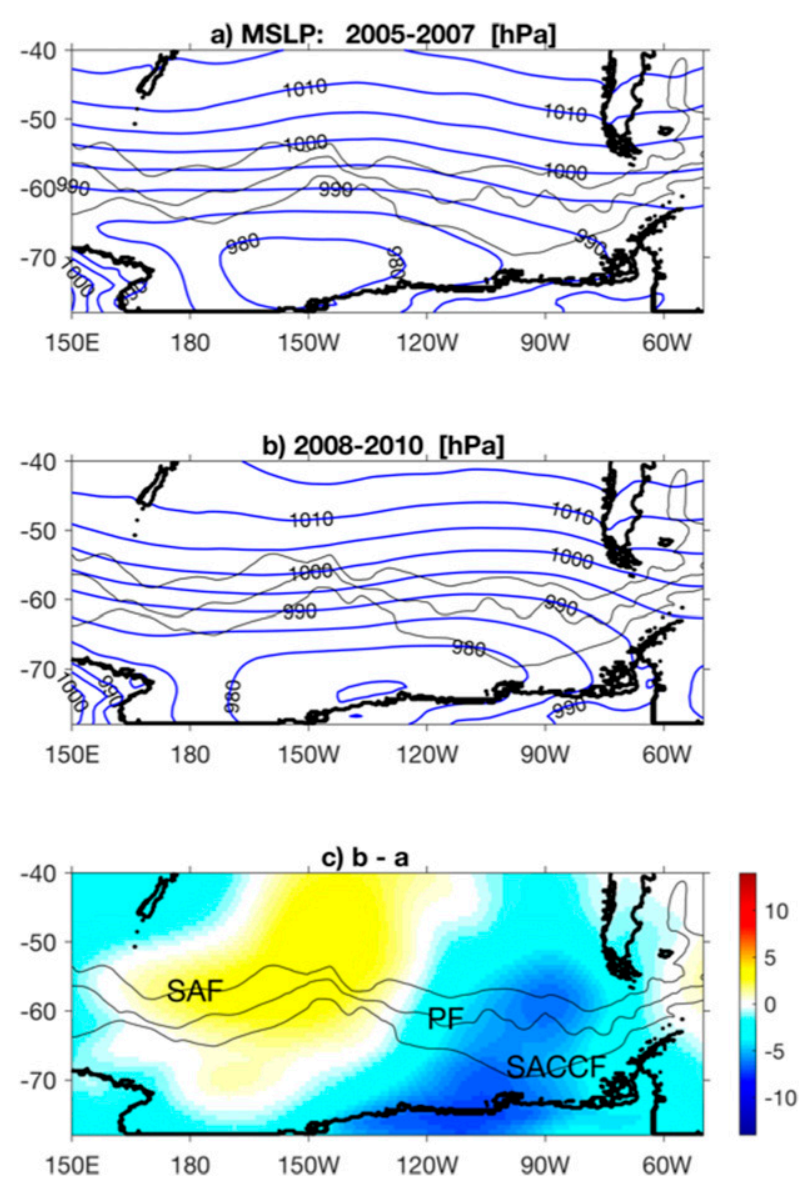

FIG. 2. Austral winter (JAS) average of mean sea level pressure from ERA-Interim, averaged over the years (a) 2005-07 and (b) 2008-10 (with contour interval $5 \mathrm{hPa}$ in both panels), and (c) the difference between the fields (hPa) shown in (a) and (b). In (c) the black contours indicate climatological positions of the Subantarctic Front (SAF), Polar Front (PF), and Southern ACC Front (SACCF), given by Orsi et al. (1995).

shortwave radiation, wind velocity, and precipitation) and ocean initial conditions, as well as the open boundary conditions at $24.7^{\circ} \mathrm{S}$. This method does not require unphysical nudging terms to be introduced in the dynamics, a fact which is important for budget calculations. Details about SOSE are provided by Mazloff et al. (2010), and more recently by Masich et al. (2015) and by Tamsitt et al. (2016). Additional documentation is also available via UCAR's Climate Data Guide (https://climatedataguide. ucar.edu/climate-data/southern-ocean-state-estimate-sose). SOSE output is available at sose.ucsd.edu.

We have analyzed the results from the 2005-10 SOSE iteration 100 , which was previously considered by Abernathey et al. (2016) and by Tamsitt et al. (2017). This iteration builds upon two separate SOSE optimizations that used different atmospheric fields for 200507 (based on the NCEP-NCAR Reanalysis 1; Kalnay et al. 1996) and for 2008-10 (based on the ERA-Interim reanalysis; Dee et al. 2011).

Abernathey et al. (2016) carried out extensive validation of SOSE iteration 100 against observations, especially with Argo observations. They showed that while the SOSE potential temperature, salinity, and potential density do not agree with Argo in every detail, within the top $700 \mathrm{~m}$ the misfit between SOSE and Argo hydrography was relatively small compared to the overall internal variability of the eddy-rich Southern Ocean. SOSE and Argo hydrography were shown to agree equally well during both time periods $2005-07$ and 2008-10 (Abernathey et al. 2016). In this work, the SOSE output has been further verified against observations and observationally based products: 1 ) quality controlled delayed mode Argo profiles, 2) their mapping to a regular grid in pressure coordinates (hereafter "mapped Argo"), 3) the RG09 Argo product, and 4) the ERA-Interim reanalysis. The mapped Argo data were created by optimally interpolating all available qualitycontrolled Argo profiles onto a $2^{\circ} \times 2^{\circ}$ grid with 100 pressure surfaces at 10-day time steps from 2005 to 2017. Where insufficient Argo data were available for mapping, values at grid points were relaxed to climatological values. Selected results of SOSE verification are shown in the appendix.

Overall, our approach is to carry out the analyses using Argo products where possible. SOSE is used whenever Argo products are too limited, either in order to have a more complete view of the region or to carry out analyses that cannot be done with Argo (e.g., the salt budget and the particle release experiment described below).

\section{b. Salt budget}

The salt budget in SOSE has been evaluated as

$$
\begin{aligned}
\frac{\partial S}{\partial t}+\nabla \cdot(\mathbf{u} S)= & Q_{S} \equiv \kappa_{h} \nabla_{h}^{2} S+\partial_{z}\left[\kappa_{v}\left(\partial_{z} S-\gamma_{S}^{t}\right)\right] \\
& +S \partial_{z}(E-P-R-\mathrm{IO}),
\end{aligned}
$$

where $\partial S / \partial t$ is the salinity tendency, $\mathbf{u}$ is the threedimensional velocity, $\nabla_{h}$ is the horizontal gradient, $\kappa_{h}$ and $\kappa_{v}$ are horizontal and vertical diffusion coefficients, $E$ is evaporation, $P$ is precipitation, $R$ is runoff, and IO is freshwater forcing by sea ice-ocean processes (all in $\mathrm{m} \mathrm{s}^{-1}$ ). The vertical flux due to unresolved processes involved in the vertical mixing of $S$ is represented by the nonlocal $K$-profile parameterization (KPP) (Large et al. 1994). It comprises two terms, representing local unresolved vertical diffusive processes in the boundary layer $\left(\kappa_{v} \partial_{z} S\right)$ and the turbulent nonlocal transport of properties $\left(\kappa_{v} \gamma_{S}^{t}\right)$. A similar formalism holds for the 
mixing of potential temperature $\theta$ (see, e.g., Cerovečki and Mazloff 2016).

\section{c. Walin analysis}

Changes in density occur as a result of air-sea buoyancy fluxes and diapycnal ocean mixing, which have their largest impacts near the ocean surface (Iudicone et al. 2008). These processes lead to water mass transformation, which changes the volume of water in the individual isopycnal layers. The Walin (1982) framework permits estimation of water mass formation (or destruction) from the convergence (or divergence) of diapycnal volume flux in individual isopycnal layers (e.g., Marshall et al. 1999; Nurser et al. 1999; Iudicone et al. 2008; Cerovečki and Marshall 2008). While ocean mixing plays a fundamental role in water mass formation in the Southern Ocean (Sloyan and Rintoul 2001; Iudicone et al. 2008; Cerovečki and Mazloff 2016), we here focus on the interannual variability in surface formation, and we neglect interior mixing. The neglect of mixing allows us to use a simpler framework: we consider water that outcrops at the surface in the potential density range $\sigma_{1}<\sigma<\sigma_{2}$. This is an outcrop window of a control volume that is bounded by the ocean surface, laterally by isopycnals $\sigma_{1}$ and $\sigma_{2}$, and below by a fixed Eulerian surface, across which we compute volume exchange with the ocean interior. Since we only consider formation by air-sea buoyancy fluxes, the diapycnal volume transport $A(\sigma, t)$, called the water mass transformation, can be obtained as an area integral of air-sea buoyancy flux $B$ over an outcrop window bounded by reference density $\sigma_{0}$ on one side and by $\sigma$ on the other side, where $\sigma_{0}$ is a reference density taken to be smaller than $\sigma$ :

$$
A(\sigma, t)=\frac{\partial}{\partial \sigma} \iint_{\sigma_{0}}^{\sigma} B d A
$$

in which $d A$ is an area element of integration, and $B$ is given by

$$
B=-\frac{\alpha Q}{C_{P}}+\rho_{0} \beta S(E-P-\mathrm{IO}),
$$

(see, e.g., Garrett et al. 1995). Here $\rho_{0}$ is a reference density of $1035 \mathrm{~kg} \mathrm{~m}^{-3}, \alpha$ is the thermal expansion coefficient, $\beta$ is the saline contraction coefficient, $Q$ is the net air-sea heat flux (the sum of latent and sensible heat flux, net shortwave and net longwave radiation), and $C_{P}$ is the specific heat. Note that $A(\sigma, t)$ is defined to be positive for flow toward denser water.

A discretized expression for water mass transformation by air-sea ice buoyancy fluxes $A(\sigma, t)$ within our control volume is (e.g., Maze et al. 2009)

$$
\begin{aligned}
A(\sigma, t) & =\frac{1}{\Delta \sigma}\left(\iint_{\sigma_{0}}^{\sigma+\Delta \sigma / 2} B d A-\iint_{\sigma_{0}}^{\sigma-\Delta \sigma / 2} B d A\right) \\
& =\frac{1}{\Delta \sigma} \iint_{\sigma-\Delta \sigma / 2}^{\sigma+\Delta \sigma / 2} B d A,
\end{aligned}
$$

indicating that $A(\sigma, t)$ is obtained as an area integral over a discrete isopycnal outcrop of $\sigma$ in the potential density range $\sigma-\Delta \sigma / 2<\sigma<\sigma+\Delta \sigma / 2$.

Finally, the water mass formation $M(\sigma, t)$ is given by the convergence of water mass transformation $A(\sigma, t)$ with respect to density. In practice $M(\sigma, t)$ is multiplied by $\Delta \sigma$ to have the same units as the transformation rate $\left(\mathrm{m}^{3} \mathrm{~s}^{-1}\right.$; expressed in Sverdrups, $\left.1 \mathrm{~Sv} \equiv 10^{6} \mathrm{~m}^{3} \mathrm{~s}^{-1}\right)$, and is obtained as

$$
M(\sigma, t)=A(\sigma-\Delta \sigma / 2)-A(\sigma+\Delta \sigma / 2) .
$$

Garrett and Tandon (1997) have shown that for accurate estimates of water mass transformation $A(\sigma, t)$, Eq. (4) should be evaluated following isopycnals as they move seasonally in time. In practice this implies that Eq. (4) should be evaluated by working with input data that have not been time averaged over an extended time period. For example, analyzing output of an ocean-sea ice coupled model with $0.25^{\circ}$ horizontal resolution, Ballarotta et al. (2013) suggested that for diagnosing the Southern Ocean water mass formation and meridional overturning, time averaging should not exceed five days.

The formation rate estimates discussed in this work were obtained from Walin analysis with daily averaged net air-sea heat flux, sea surface temperature (SST), and $E-P$ from ERA-Interim reanalysis, combined with monthly averaged salinity (interpolated to daily values) from the uppermost layer (2.5-m depth) of the RG09 Argo product. Although satellite SST is readily available, satellite salinity does not provide sufficient accuracy or resolution, particularly at high latitudes, and the Argo-derived salinity does not match the temporal resolution of the SST product or the reanalysis $E-P$ and surface fluxes. This mismatch in data sources and spatiotemporal sampling is a potential source of error in the water-mass formation estimates, as the individual features (such as the ACC fronts) may not be collocated in the two datasets.

\section{d. Particle release experiment}

The particle release experiment was conducted offline using Octopus (https://github.com/jinbow/Octopus), described by Tamsitt et al. (2017) and van Sebille et al. (2017). Passive particles were advected with archived daily-averaged velocity output from the 2005-10 SOSE iteration 100 . When particles are within the mixed layer, 
defined in terms of vertical derivatives of density, a random reshuffle of the vertical position of the particle within the mixed layer is included every five days to represent turbulence that is not explicitly resolved in the SOSE velocities. This representation of mixed layer processes is ad hoc, and further work is needed to characterize errors associated with unresolved mixed layer dynamics. Our results are also subject to errors associated with unresolved turbulence in the ocean interior; however, particle release experiments suggest the effects of parameterized interior turbulence are higher order and should not significantly impact our results (Tamsitt et al. 2017).

Particles were released every five days at the sea surface in each latitude-longitude model grid box in which the archived 5-day averaged salt flux due to sea ice processes indicated freshening from sea ice melt. This resulted in a total of more than one million particle trajectories. Particle positions were integrated for a total of three years, with a half day time step for particle advection. We here use the results for particles released during year 2008, and advected for three years following their release, focusing on particles that at some point during that time reached the geographical location of the Pacific SAMWs [here considered north of the climatological position of the Subantarctic Front (SAF) given by Orsi et al. (1995), in the longitudinal range $120^{\circ}-70^{\circ} \mathrm{W}$; see Fig. A1 in the appendix]. We focus on the year 2008 in order to examine the role of enhanced sea ice melt following that year's enhanced sea ice export from the Ross Sea. The sea ice export led to observed freshening in the SEPSAMW density range during the time period 2008-10.

Particles are "tagged" with the freshwater flux at their release location at the time of release [similar to the method of volume transport tagging of Tamsitt et al. (2017)]. This allows us to use particle weighting for particle distributions: we sum the freshwater flux assigned to each particle at each location and normalize by the total freshwater flux of all the particles. In this way particles initially assigned a greater freshwater flux have a larger contribution to the particle pathway distributions.

\section{e. SAMW volume and properties in the southeast Pacific in 2005-10}

Since we focus on Pacific SAMWs, we first briefly describe their location and their density ranges using the RG09 Argo product. Two regions of deep winter mixed layers, associated with two SAMW low-PV pools, are present in the South Pacific (Fig. 3). In this work we consider SAMW to have $\mathrm{PV}<40 \times 10^{-12} \mathrm{~m}^{-1} \mathrm{~s}^{-1}$. (The
low-PV pools in SOSE are shown in Fig. A1.) In the southeast Pacific, close to the coast of Chile, is the SEPSAMW low-PV pool (Fig. 3). This is a denser variety of SAMW. Considering the volume of water with $\mathrm{PV}<40 \times 10^{-12} \mathrm{~m}^{-1} \mathrm{~s}^{-1}$ as a function of density in the "east box" $\left(114^{\circ}-72^{\circ} \mathrm{W}, 47^{\circ}-59^{\circ} \mathrm{S}\right)$ that encompasses the SEPSAMW formation region (Fig. 3) shows that its volume peaks in the $\sigma_{\theta}=26.95-27.1 \mathrm{~kg} \mathrm{~m}^{-3}$ density range (Figs. 4c,d), similar to Sallée et al.'s (2010b) estimate of $\sigma_{\theta}=27.1 \mathrm{~kg} \mathrm{~m}^{-3}$.

The other region of deep winter mixed layers shown in Fig. 3, located in the central Pacific, near the Eltanin Fracture Zone $\left(140^{\circ} \mathrm{W}\right)$, is the central Pacific SAMW formation region (hereafter CPSAMW; Fig. 3). This is a lighter variety of SAMW. Considering the volume of water with $\mathrm{PV}<40 \times 10^{-12} \mathrm{~m}^{-1} \mathrm{~s}^{-1}$ as a function of density in the "west box" $\left(143^{\circ}-114^{\circ} \mathrm{W}, 47.3^{\circ}-55.3^{\circ} \mathrm{S}\right)$ that encompasses the CPSAMW low-PV pool (Fig. 3) shows that its volume peaks in the $\sigma_{\theta}=26.95$ $27.1 \mathrm{~kg} \mathrm{~m}^{-3}$ density range (Figs. $4 \mathrm{c}, \mathrm{d}$ ). This is also similar to the estimate of Sallée et al. (2010b), who showed that low-PV water in this region has a density $\sigma_{\theta}$ between 26.9 and $27.0 \mathrm{~kg} \mathrm{~m}^{-3}$ (Sallée et al. 2010b).

In our analysis we thus define SAMW in the South Pacific (comprising CPSAMW and SEPSAMW) as water in the density range $\sigma_{\theta}=26.85-27.1 \mathrm{~kg} \mathrm{~m}^{-3}$ with $\mathrm{PV}<40 \times 10^{-12} \mathrm{~m}^{-1} \mathrm{~s}^{-1}$. We consider AAIW density range to be the density range at the salinity minimum that is denser than SEPSAMW (approximately $\sigma_{\theta}=$ $\left.27.1-27.3 \mathrm{~kg} \mathrm{~m}^{-3}\right)$.

\section{Cooling and freshening in the high-latitude southeast Pacific in 2008-10 compared to 2005-07}

\section{a. Interannual atmospheric, oceanic, and cryospheric variability}

The location of the ASL strongly influences regional Antarctic climate, often introducing temperature, precipitation, and sea ice anomalies that have the opposite sign in the Ross Sea compared to the Antarctic Peninsula region (Raphael et al. 2016). In 2008-10, compared to 2005-07, the ASL deepened and moved toward the east (Figs. $1 \mathrm{~b}$ and 2 ). We here consider changes in winter [July-September (JAS)] conditions (because this is the key season for SAMW formation) between these two time periods.

In the winter (JAS) 2008-10 zonal wind stress along the ACC strengthened, especially in the southeast Pacific and in the Amundsen Sea, while in the Bellingshausen Sea zonal wind stress weakened (Fig. 5a). Both anomalies reflect a local meridional displacement 

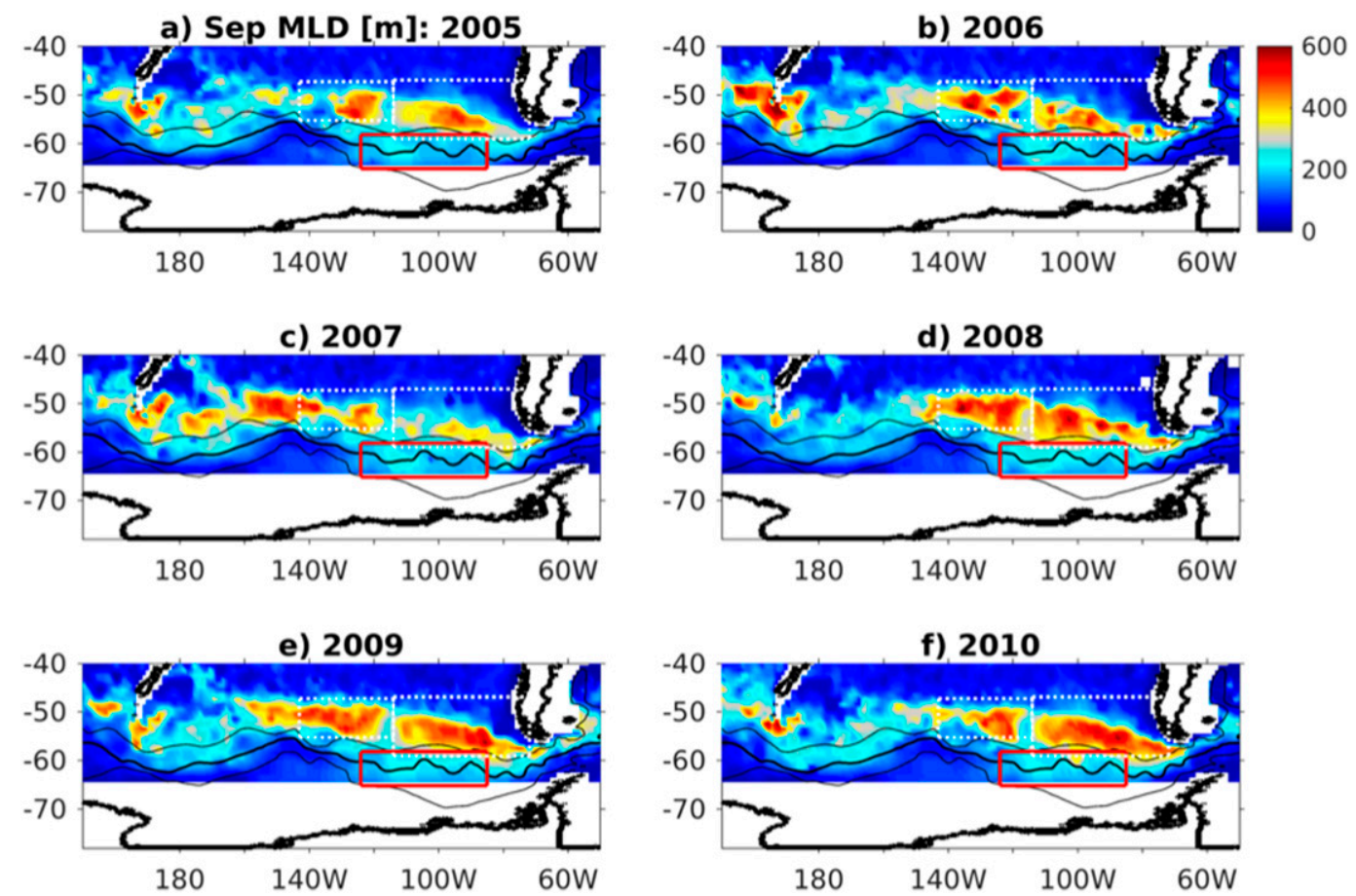

FIG. 3. September monthly mean mixed layer depths from the RG09 Argo product for the years 2005-10. Mixed layer depths are computed using a threshold method, as the depths where density has increased by $0.03 \mathrm{~kg} \mathrm{~m}^{-3}$ from its surface value. White dashed boxes indicate the locations of CPSAMW and SEPSAMW identified in the text (section 2$)$ as the western box $\left(143^{\circ}-114^{\circ} \mathrm{W}, 47.3^{\circ}-55.3^{\circ} \mathrm{S}\right)$ and the eastern box $\left(114^{\circ}-72^{\circ} \mathrm{W}, 47^{\circ}-59^{\circ} \mathrm{S}\right)$. The red box $\left(124^{\circ}-85^{\circ} \mathrm{W}, 58^{\circ}-65.7^{\circ} \mathrm{S}\right)$ encompasses the region of strong freshening in the years $2008-10$ compared to $2005-07$ (see Fig. 8).

poleward of zonal westerlies associated with changes in curvature and/or intensity of the ASL that strongly influence the temperature of both SEPSAMW and AAIW (C13). Wintertime surface ocean heat loss increased in the ACC latitude range and equatorward of it, in the central South Pacific and to a lesser extent in the eastern South Pacific, affecting both SAMW low-PV regions shown in Fig. 3.

In JAS of 2008-10, strengthened southerly winds on the western flank of the ASL advected colder and drier continental air over the eastern Ross Sea and the Amundsen Sea. In the sector with the strongest increase in southerly winds, the SST decreased and wintertime surface ocean heat loss increased (Figs. 5c,d). Enhanced southerly winds also drove stronger northward sea ice transport (Fig. 5f), increasing ice formation to the south in the divergent pack (Holland and Kimura 2016). In this way, ice dynamics and thermodynamic effects both contributed to an increase in the sea ice extent and volume, in agreement with Holland and Kwok (2012) and Holland et al. (2014). The sea ice edge in the Amundsen Sea sector thus extended farther north and east (Fig. 5g).

At the same time, in the Bellingshausen Sea, enhanced northerly winds advected warm air, decreasing both wintertime surface ocean heat loss and meridional sea ice volume transport (Figs. 5d,f). The winds thus impeded the ice advance dynamically, while also reducing ice growth through warmer, wetter maritime air anomalies. In 2008-10, the sea ice edge and consequently the meltwater from the Bellingshausen Sea were located farther poleward than in the weaker ASL years. For this meltwater to affect the SEPSAMW formation region, it would have had to be transported farther northward than during the weaker ASL years, while at the same time the zonal winds and associated northward Ekman transport were weaker.

Because the isopycnals are very closely packed in the ACC latitude band, even relatively small changes in sea ice transport and melt location, as observed in 2008-10, can cause significant interannual variability in regional water mass properties. We thus next consider interannual variability of $\theta$ and $S$ oceanic conditions in the South Pacific SAMW.

\section{b. Interannual variability of oceanic conditions in the southeast Pacific from Argo observations}

Interannual variability of $\theta$ and $S$ oceanic conditions in the South Pacific are first considered using the 

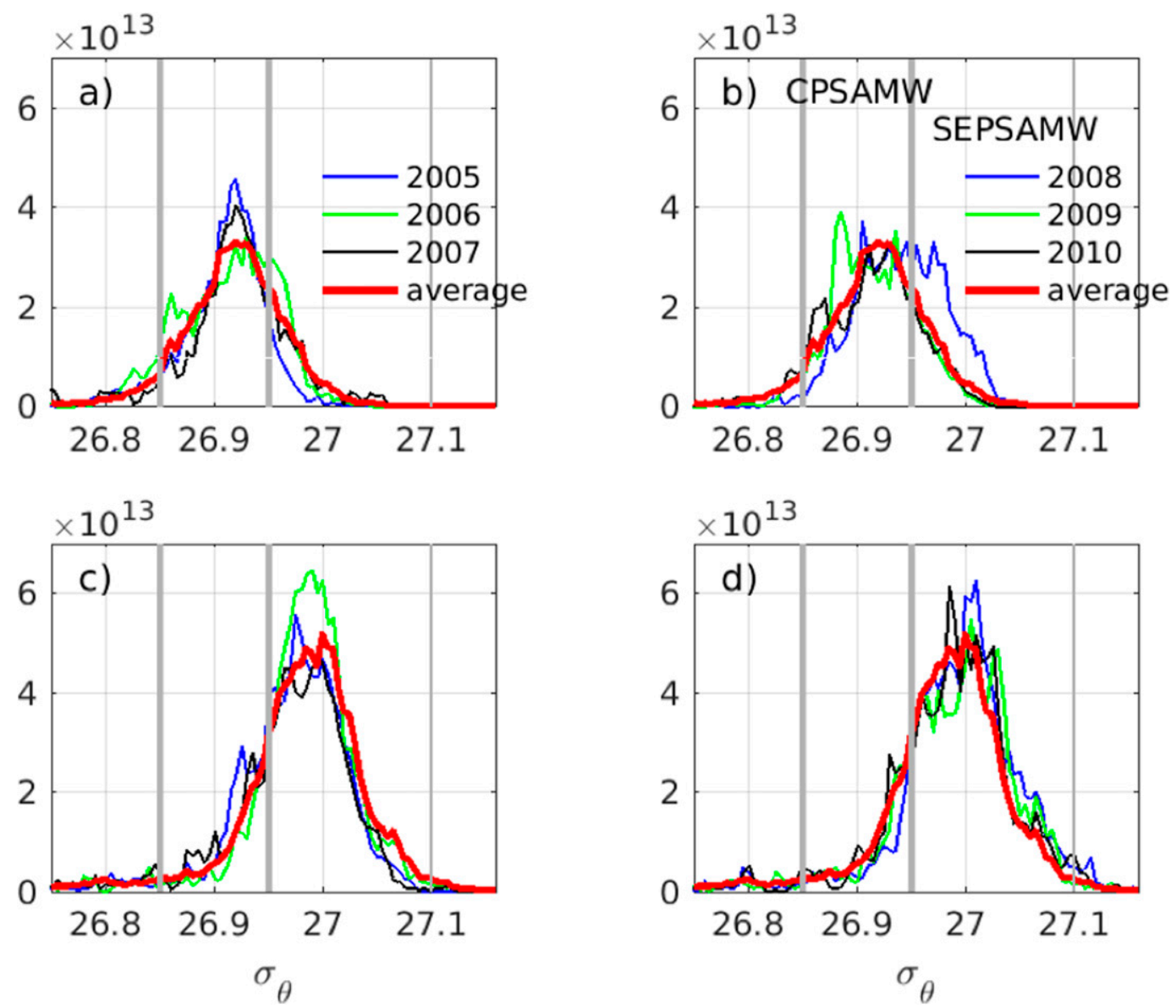

FIG. 4. From the RG09 Argo product, annually averaged volume of water with $\mathrm{PV}<40 \times 10^{-12} \mathrm{~m}^{-1} \mathrm{~s}^{-1}$, binned into potential density bins $0.005 \mathrm{~kg} \mathrm{~m}^{-3}$ wide, in (a), (c) the western box and (b), (d) the eastern box shown in Fig. 3. The density range of SAMW in the western box is approximately $\sigma_{\theta}=26.85-26.95 \mathrm{~kg} \mathrm{~m}^{-3}$, and the density range of SAMW in the eastern box is approximately $\sigma_{\theta}=26.95-27.1 \mathrm{~kg} \mathrm{~m}^{-3}$; these are the density ranges of the CPSAM and SEPSAMW respectively. The density ranges of these two water masses are also indicated by vertical gray lines.

quality-controlled dataset of Argo profiles. The seasonal signal was removed from each profile by subtracting a monthly mean climatological profile from a $2^{\circ} \times 2^{\circ}$ mapping of Argo profiles between 2005 and 2014. These $\theta$ and $S$ anomalies were then averaged vertically for each profile over the depth range of SAMW $\left(\mathrm{PV}<40 \times 10^{-12} \mathrm{~m}^{-1} \mathrm{~s}^{-1}\right.$, and $\left.\sigma_{\theta}=26.85-27.1 \mathrm{~kg} \mathrm{~m}^{-3}\right)$. The vertically averaged anomalies were subsampled over the so-called west box and east box (shown in Figs. 3 and 7).

In the west box, temperature decreased from 2006 to 2009 , while salinity decreased from late 2008 until 2011 (Figs. 6a,c). Focusing on the time period 2008$10, S$ and $\theta$ decreases were $d S / d t=-0.0195 \pm 0.0027$ $S_{P} \mathrm{yr}^{-1}$ (where $S_{P}$ is the practical salinity) and $d \theta / d t=-0.034 \pm 0.029^{\circ} \mathrm{Cyr}^{-1}$ (where uncertainties represent \pm two standard deviations). In the west box, the CPSAMW thickness was large in 2008 (not shown) when SAM was strong and positive, in agreement with Sallée et al. (2010a). Over the time period 2008-10 thickness decreased at a rate $-40.4 \pm 19.6 \mathrm{~m} \mathrm{yr}^{-1}$ (not shown).

Both $S$ and $\theta$ also decreased in the east box, but this decrease started approximately a year later and was smaller in magnitude than in the west box. As in the west box, the salinity decrease started later than the temperature decrease (Figs. 6b,d). Focusing on the time period 2008-10, in the east box the $S$ and $\theta$ decreases were $d S / d t=-0.0077 \pm 0.0010 S_{P} \mathrm{yr}^{-1}$ and $d \theta / d t=$ $-0.067^{\circ} \pm 0.012^{\circ} \mathrm{Cyr}^{-1}$, while the SEPSAMW layer thickened by $84.1 \pm 14 \mathrm{~m} \mathrm{yr}^{-1}$ (not shown). Averaged over both boxes, changes were $d S / d t=-0.0128 \pm 0.0012 S_{P} \mathrm{yr}^{-1}$ and $d \theta / d t=-0.056^{\circ} \pm 0.014^{\circ} \mathrm{Cyr}^{-1}$, while thickness increased at a rate $36.6 \pm 11.6 \mathrm{~m} \mathrm{yr}^{-1}$.

Maps of winter (JAS) $\theta$ and $S$ obtained from the same optimally interpolated Argo dataset show strong 
a) Difference in: zonal wind stress $\left[\mathrm{N} \mathrm{m}^{-2}\right]$

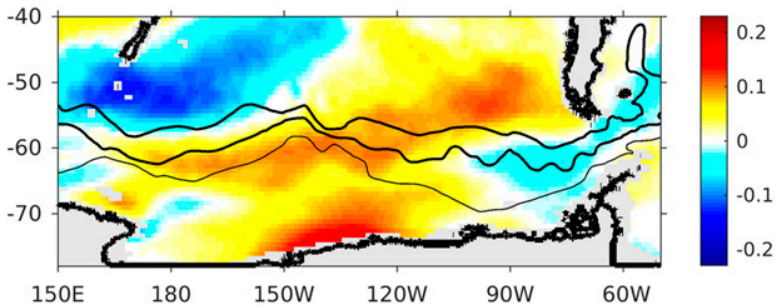

c) SST [ $\left.{ }^{\circ} \mathrm{C}\right]$

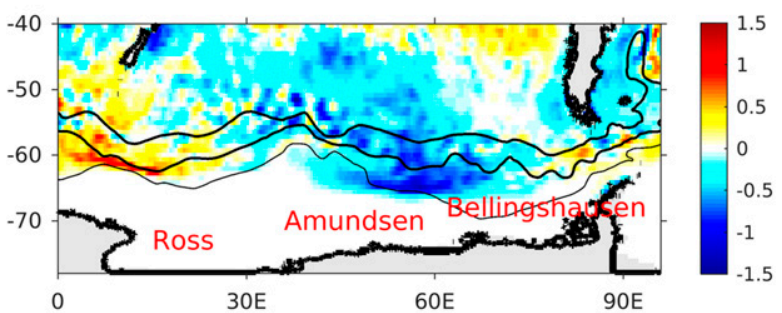

e) Zonal ice volume transport $\left[\mathrm{m}^{3} \mathrm{~s}^{-1}\right]$

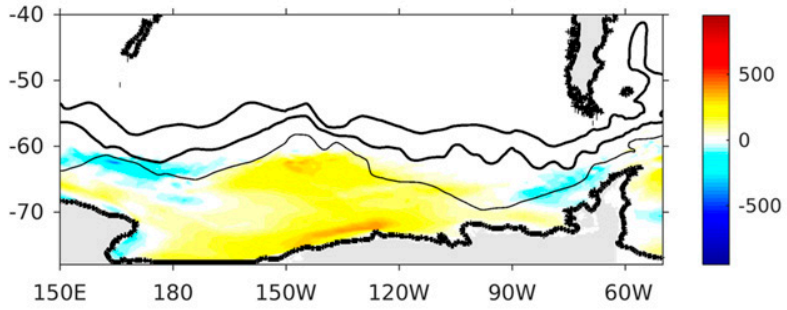

g) Ice concentration

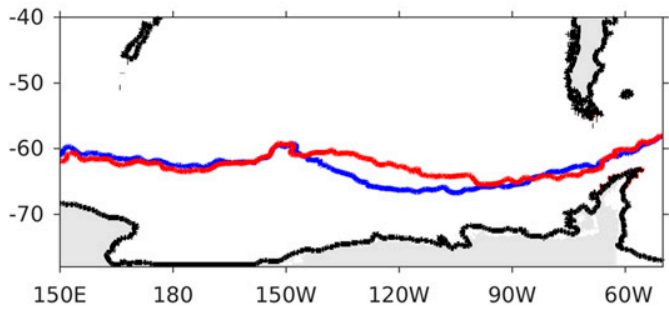

b) Meridional wind stress $\left[\mathrm{N} \mathrm{m}^{-2}\right]$

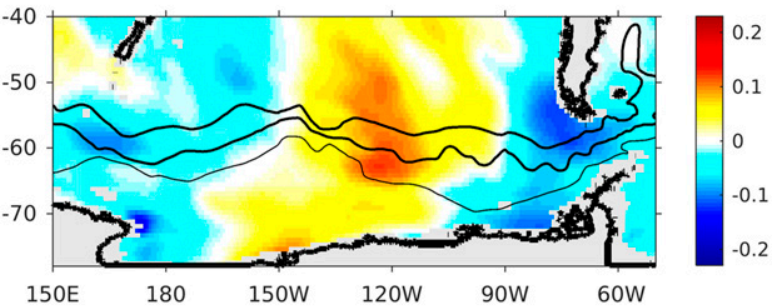

d) Surface heat flux $\left[\mathrm{W} \mathrm{m}^{-2}\right]$

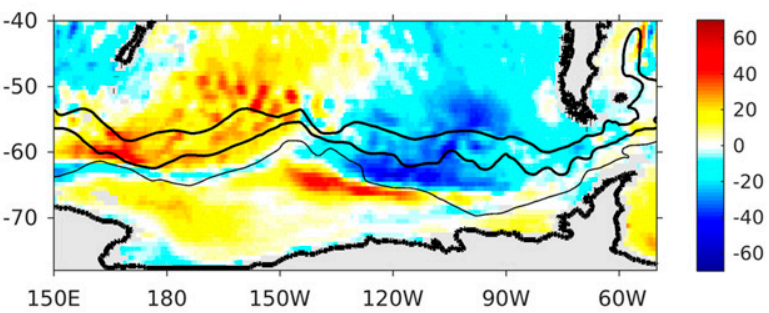

f) Meridional ice volume transport $\left[\mathrm{m}^{3} \mathrm{~s}^{-1}\right]$

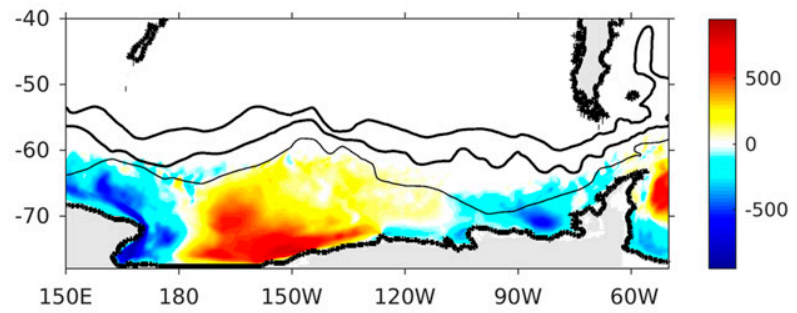

FIG. 5. Austral winter (JAS) average in 2008-10 minus winter average in 2005-07 for (a) zonal and (b) meridional wind stress ( $\mathrm{N} \mathrm{m}^{-2}$ ), (c) sea surface temperature $\left({ }^{\circ} \mathrm{C}\right),(\mathrm{d})$ net surface heat flux $\left(\mathrm{W} \mathrm{m}^{-2}\right.$, with negative values indicating ocean heat loss), and (e) zonal and (f) meridional sea ice volume transport $\left(\mathrm{m}^{3} \mathrm{~s}^{-1}\right)$. (g) JAS sea ice edge time average for 2005-07 (blue) and 2008-10 (red), here defined by $15 \%$ sea ice concentration. Note that (a)-(d) are from ERA-Interim and (e)-(g) from SOSE. The locations of the Ross Sea, Amundsen Sea, and Bellingshausen Sea are indicated in (c); black contours indicate climatological positions of the SAF, PF, and SACCF given by Orsi et al. (1995). The 2005-10 time mean conditions are provided in the online supplemental material.

negative $\theta$ and $S$ anomalies in the western high latitude Pacific in 2008 and 2010 (Fig. 7). In 2008, the strongest anomaly was located immediately poleward of the western box (Fig. 7a), while at the same time, the SEPSAMW was anomalously warm and salty in the eastern box (Figs. 7a,b). In 2009, the negative $\theta$ and $S$ anomalies were located farther east than in 2008 , while in 2010 , a strong negative $\theta, S$ anomaly was evident throughout the entire longitude range considered (Fig. 7).

\section{c. Interannual variability of oceanic conditions in the southeast Pacific from SOSE and the RG09 Argo product}

We next briefly consider changes in $\theta$ and $S$ in SOSE and in the RG09 Argo product, which are the main tools 

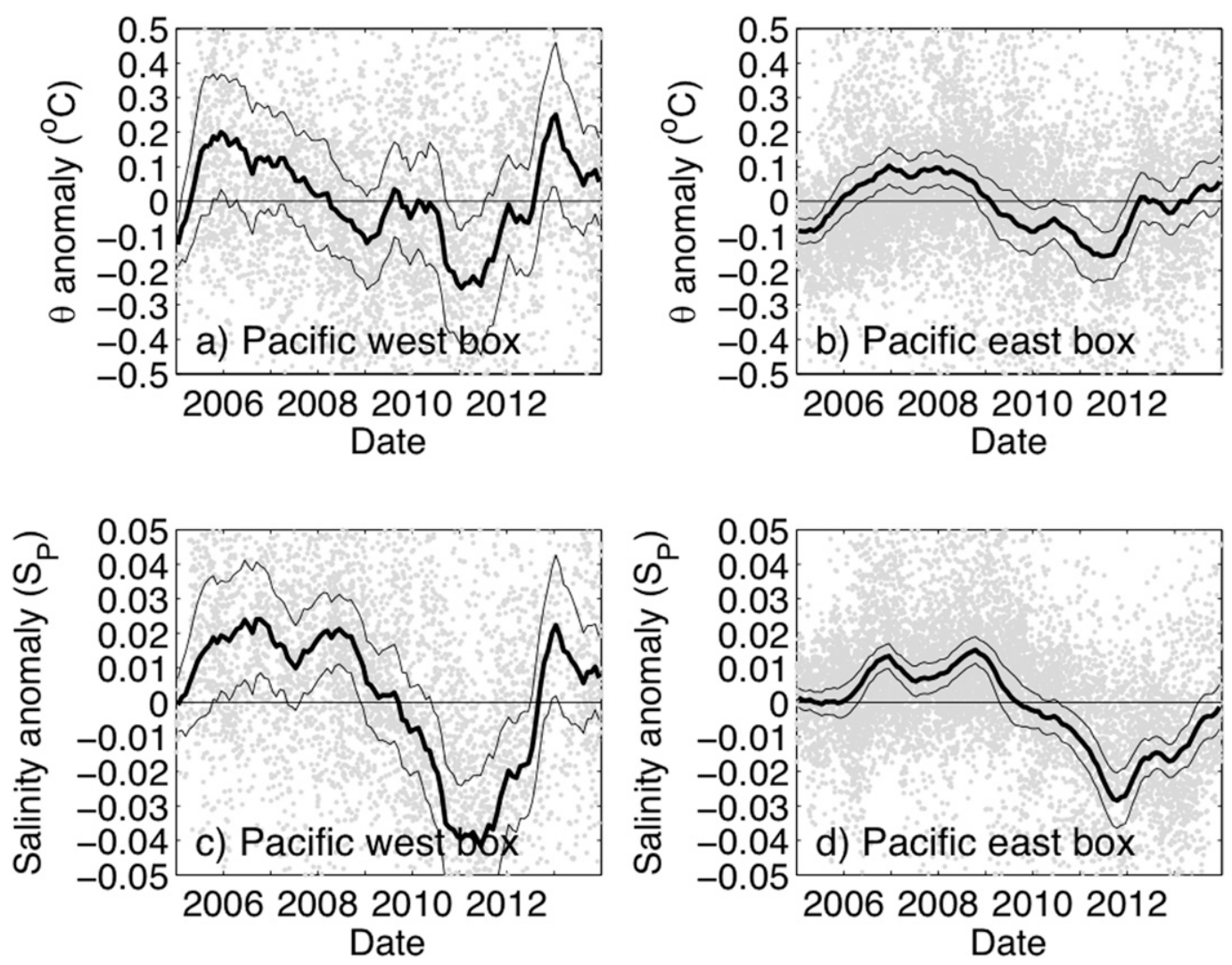

FIG. 6. Argo-profile-derived SAMW property anomalies for 2005-14, with seasonal variability removed for the (a),(c) western and (b),(d) eastern boxes (see also Fig. 7) for (top) potential temperature and (bottom) practical salinity. SAMW anomalies are defined as described in the text (section 3b). Dots indicate individual profile anomalies. Bold lines show a 3-month running mean of monthly mean anomalies, and fine lines indicate twice the standard error of the mean (2 times the standard deviation divided by $\sqrt{N}$, where $N$ is number of observations).

for our analysis. While both products show strong freshening in 2008-10 compared to 2005-07 (Figs. 8a-f), the Argo product does not extend sufficiently poleward to include the region of strongest freshening in SOSE, thus precluding direct comparison. However, salinity, averaged zonally over a longitudinal range of strongest freshening $\left(124^{\circ}-85^{\circ} \mathrm{W}\right)$ reveals a strong negative anomaly extending equatorward over a broad latitudinal and depth range in both SOSE and in the RG09 Argo product (Figs. 8a,b), suggesting that this freshening is a robust signal. Freshening is evident both in the AAIW and in the SAMW density range (Figs. 8a,b).

In SOSE, strong freshening occurred in the Ross and Amundsen Sea sectors, with a tongue of strong negative salinity anomaly in the ACC latitude range extending east of the Pacific-Antarctic Ridge, where the ACC turns sharply southeastward (Figs. 8c-f). Both ERA-Interim (not shown) and SOSE show an increase in precipitation in this region (Fig. 8h). In SOSE, increases in freshwater flux by precipitation and by sea ice melt were comparable in magnitude (Figs. 8g,h). This region is collocated with the region of strongest austral winter SST decrease and increase in surface ocean heat loss, centered approximately at $120^{\circ} \mathrm{W}$, between the Southern Antarctic Circumpolar Current Front (SACCF) and SAF (Figs. 5c,d). This suggests that both cooling and freshening in this region were at least partly caused by an increase in sea ice melt in the years 2008-10 compared to 2005-07.

Similar to the SOSE estimates, satellite observations analyzed by Haumann et al. (2016) also showed anomalously strong sea ice freshwater flux in the southeast Pacific in 2008 compared to the time average over the $25-\mathrm{yr}$ period (1982-2008) analyzed by Chung et al. (2018).

Our results thus suggest that sea ice melt and precipitation may potentially play equally important roles in the interannual variability of both SAMW and AAIW properties. Tsukernik and Lynch's (2013) detailed assessment of ERA-Interim fields agrees with our findings that show a greater meridional freshwater transport into the Ross Sea sector in 2008-10 compared to 2005-07, but it shows no clear correlation with the Southern Oscillation index or SAM over longer times. 

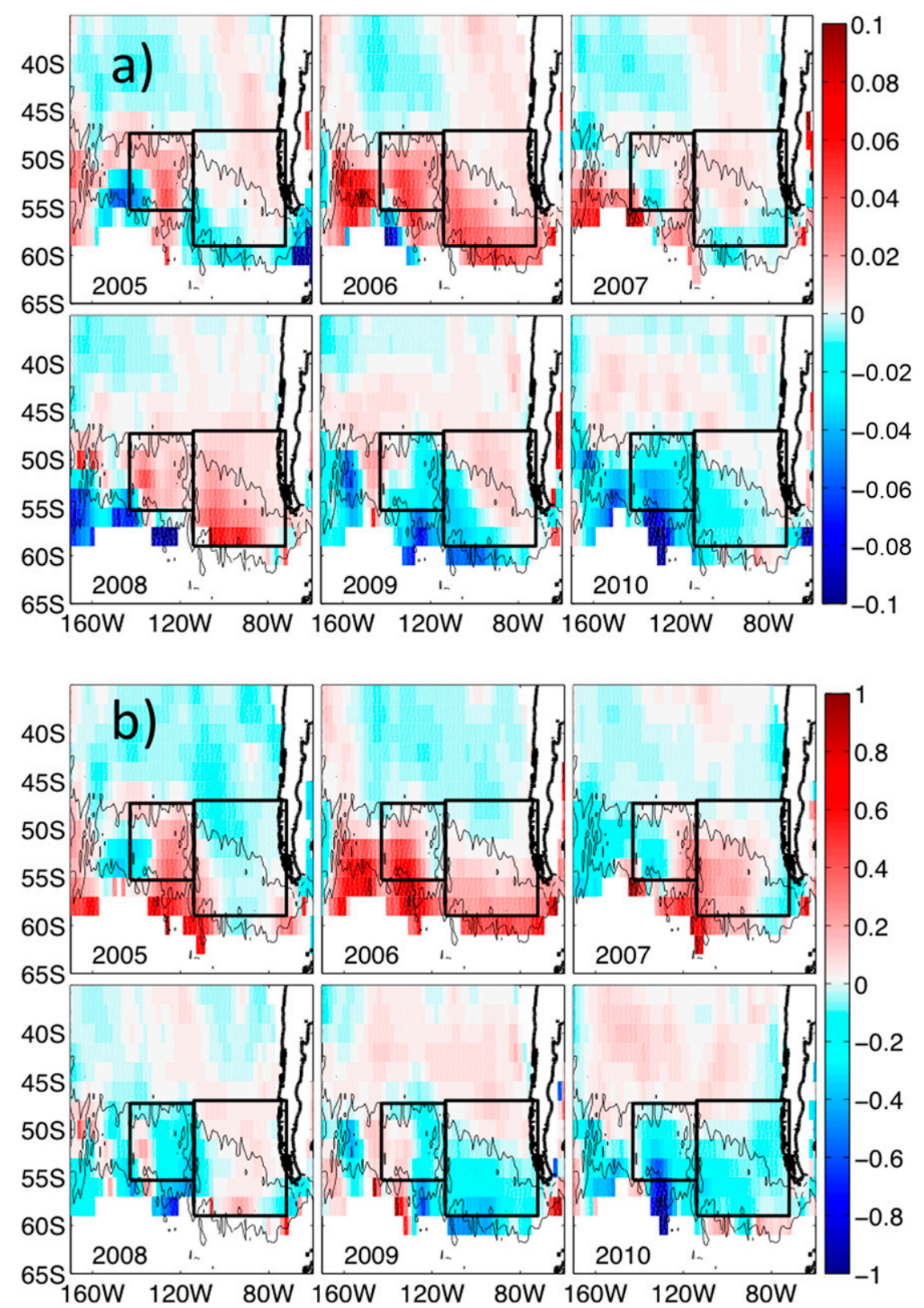

FIG. 7. Spatial maps of the SAMW winter (JAS) property anomalies (with climatology removed) for years $2005-10$ from a $2^{\circ} \times 2^{\circ}$ gridded optimal interpolation of Argo profiles for (a) salinity and (b) potential temperature. Bold lines indicate the western and eastern boxes described in the text. Fine lines show the time-averaged boundary of deep winter mixed layers. These are defined as regions where the maximum mixed layer in the period $2005-10$ exceeds $300 \mathrm{~m}$.

The horizontal distribution of freshening in the SAMW density range is similar to that in the nearsurface layer (Figs. 8e,f compared to Figs. 8c,d). This suggests that in the years 2008-10 some of the meltwater that typically feeds AAIW (Saenko and Weaver 2001) also freshened the lighter SAMW density range.

Freshening in 2008-10 relative to 2005-07 is larger in SOSE than in the RG09 Argo product; this is possibly because the latter has been obtained using objective analysis, which reverts to the prior climatological background estimate of no change when observations are insufficient, whereas SOSE reverts to a prior model solution, and thus the Argo product is designed to yield a lower variability. While the magnitude of freshening estimated from the RG09 Argo product is similar to that from direct observations discussed in the previous 
Salinity difference: SOSE [psu]

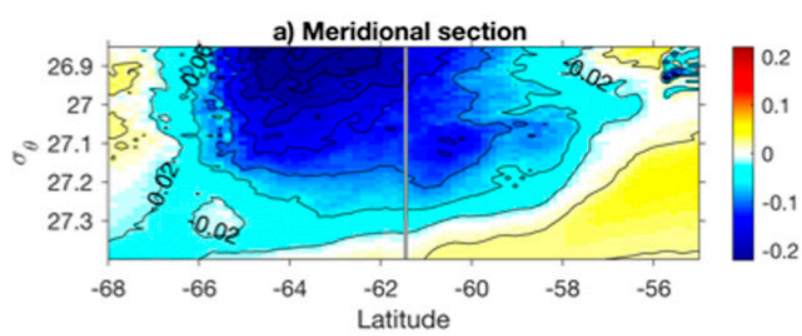

c) Top $50 \mathrm{~m}$

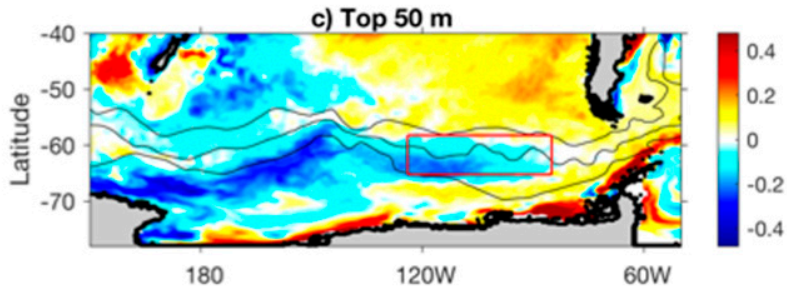

e) SAMW density range
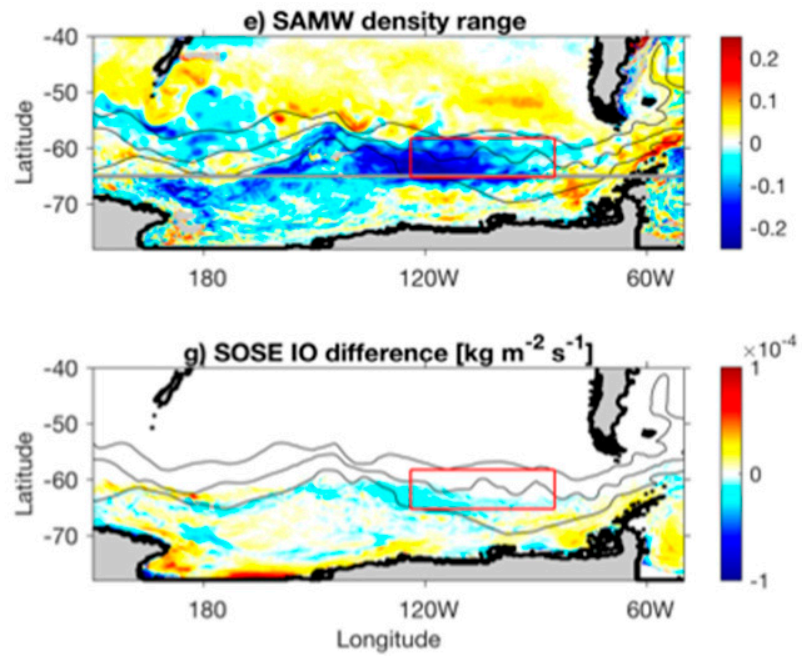

Salinity difference: Argo [psu]
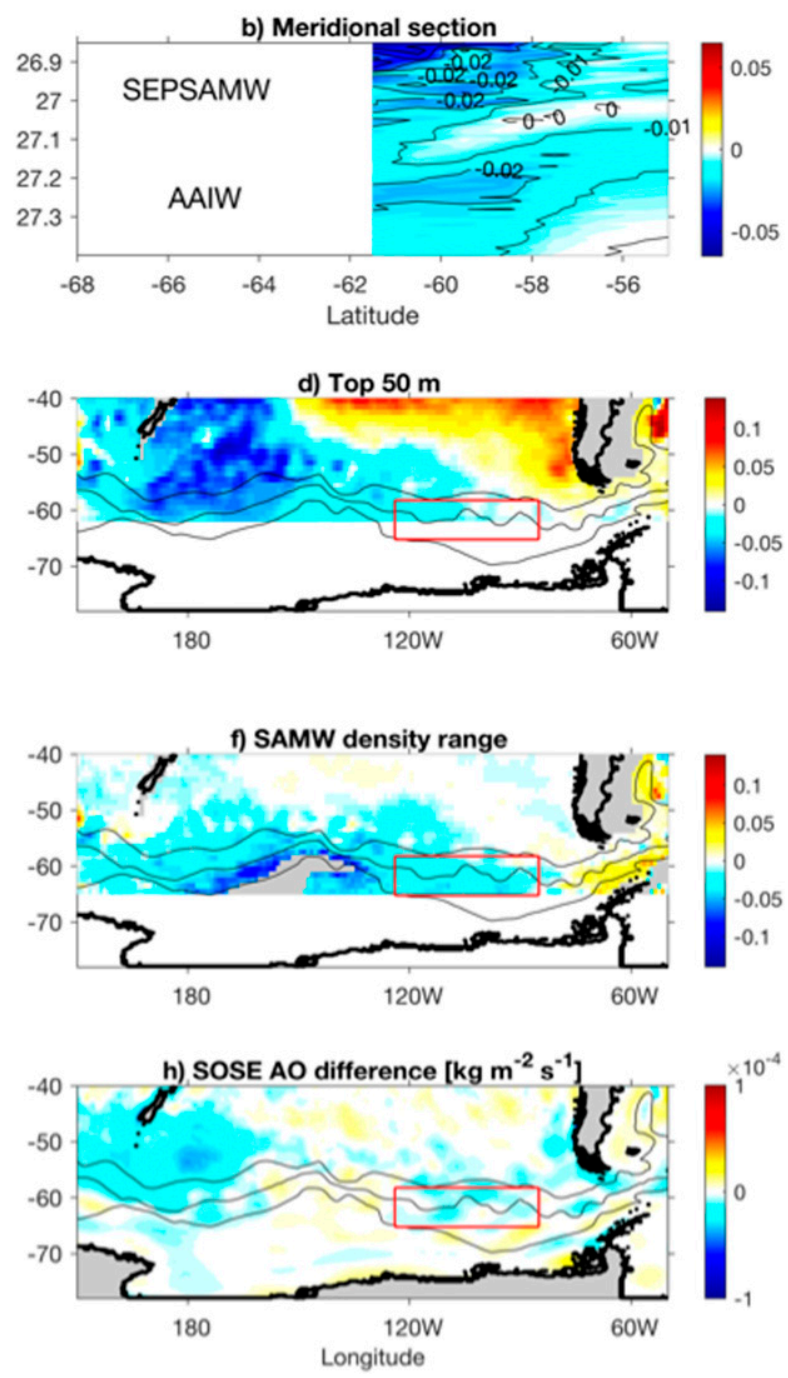

FIG. 8. Averages over 2008-10 minus averages over 2005-07 from (left) SOSE and (right) RG09 Argo data: (a),(b) salinity averaged in potential density bins with width $\sigma_{\theta}=0.01 \mathrm{~kg} \mathrm{~m}^{-3}$, over the longitudinal range of the region of strongest freshening [indicated by the red box in (c)-(h), $\left.124^{\circ}-85^{\circ} \mathrm{W}, 58^{\circ}-65.7^{\circ} \mathrm{S}\right]$, (c),(d) salinity, vertically averaged over the top $50 \mathrm{~m}$, and (e),(f) salinity averaged over the density range $\sigma_{\theta}=26.85-27.1 \mathrm{~kg} \mathrm{~m}^{-3}$ that includes both varieties of Pacific SAMW, locations of which were shown in Fig. 4. (g) SOSE-derived sea ice freshwater flux (IO) and (h) SOSE-derived atmosphere-ocean freshwater flux (AO), where negative values indicate freshening and positive values indicate a salinity increase $\left(\mathrm{kg} \mathrm{m}^{-2} \mathrm{~s}^{-1}\right)$. Gray lines in (a) and (e) indicate the southernmost extent of the RG09 Argo product. In (c)-(h) black contours indicate climatological positions of the SAF, PF and SACCF given by Orsi et al. (1995). The gray region immediately equatorward of the SACCF in (e) reflects the fact that in the years 2005-07 there was no water in the Pacific SAMW density range at this location. Note different scales for salinity difference in (a), (c), and (e) from SOSE and in (b), (d), and (f) from the RG09 Argo product.

section, freshening in SOSE is likely too strong, although the pattern of freshening is similar between all three products considered (Figs. 5e,f).

\section{d. Salt budget in SOSE in the region of the strongest freshening}

We next consider the region of strongest freshening, located poleward of the two SAMW low PV pools (the box $124^{\circ}-85^{\circ} \mathrm{W}, 58^{\circ}-65.7^{\circ} \mathrm{S}$; Fig. 3). This box straddles the Polar Front (PF), and in its southwestern part, it encompasses the region where sea ice cover extended much farther north and east in 2008-10 than in 2005-07 (Fig. 9). To assess the relative importance of various physical processes for salinity changes in this box, we diagnose the SOSE salt budget given by Eq. (1). All terms of the salt budget were binned into density bins of 

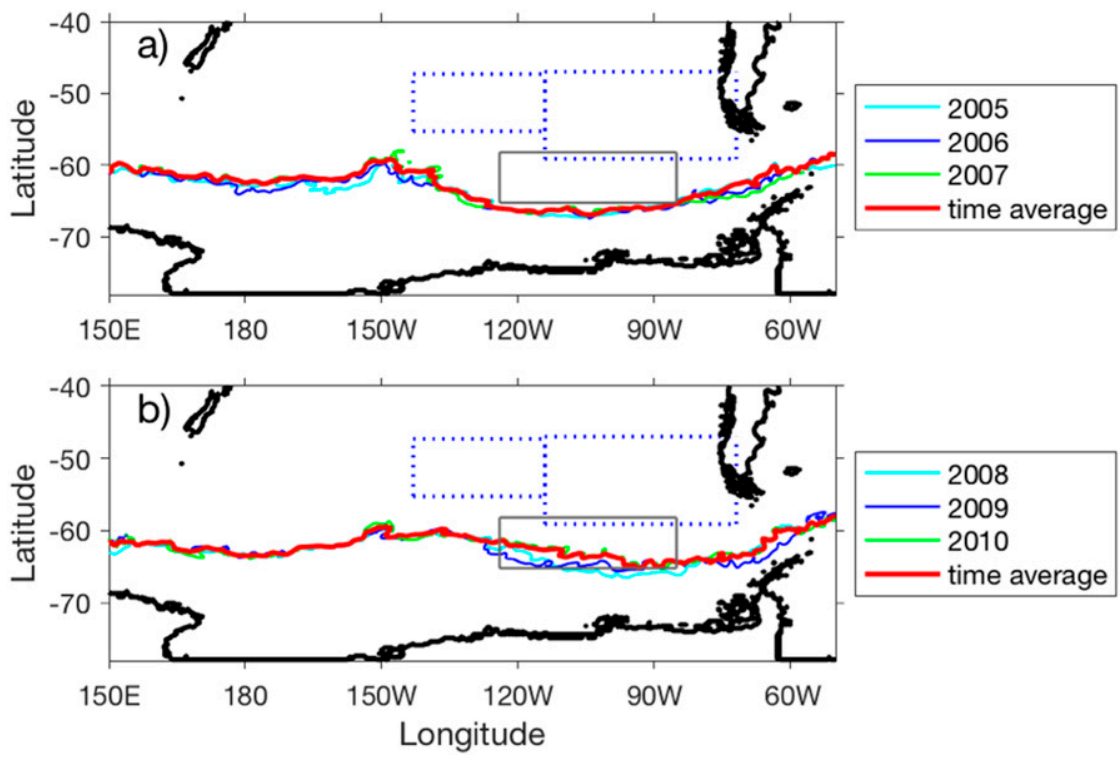

FIG. 9. September monthly mean sea ice edge (defined by $15 \%$ sea ice concentration) from SOSE over the years (a) 2005-07 and (b) 2008-10, with the time mean over the two periods indicated by the thick red line. The gray box indicates the region in which the salt budget has been diagnosed (see Fig. 10). Blue dashed boxes encompass the locations of CPSAMW and SEPSAMW identified in the text as the western box $\left(143^{\circ}-114^{\circ} \mathrm{W}, 47.3^{\circ}-55.3^{\circ} \mathrm{S}\right)$ and the eastern box $\left(114^{\circ}-72^{\circ} \mathrm{W}, 47^{\circ}-59^{\circ} \mathrm{S}\right)$.

width $\sigma_{\theta}=0.01 \mathrm{~kg} \mathrm{~m}^{-3}$, and averaged over the geographical location of the box.

While strong seasonal freshening in the SAMW density range is observed in austral spring and early summer (October-January) of each year 2008-10, the strongest freshening, acting over a broad density range, occurred in 2008 (Fig. 10a). It was caused by a strong local surface freshwater flux, predominantly by precipitation, augmented by much weaker freshening by sea ice melt (Figs. 10a,d,e,f). Much weaker freshening in the SAMW density range continued in 2009 , driven by advection and mixing (Figs. 10b,c). This freshening by advection in 2009 was in contrast to the salinity increases in 2008 and 2010 (Fig. 10b). Both freshening by advection and by mixing may reflect either advection by the ACC or cross-frontal exchange, bringing colder, polar waters north of the SAF (Holte et al. 2013; Sloyan et al. 2010).

\section{Two modes of the SEPSAMW in 2008}

Analyzing observations from the Drake Passage region, NG09 identified two modes of SAMW in 1998; a southern mode was cold and fresh, and a northern mode was warm and salty. They attributed the southern mode to strong equatorward injection of cool and fresh Antarctic Surface Water driven by exceptionally strong zonal winds caused by constructive interference between - ENSO and +SAM. They attributed the northern mode to anomalously weak early-winter convection associated with the closing phase of the pronounced El Niño of 1997/98, indicating that ENSO is a major driver of SST anomalies in the southeast Pacific. While obviously it is not possible to generalize here from the analysis of only one event, we note the similarity of atmospheric and oceanic conditions in 2008 and in 1998.

Volume estimates in the two low-PV pools (Fig. 4), combined with $\theta$ and $S$ estimates from Argo profiles shown in Fig. 6, similarly suggest the existence of two modes of SAMW in 2008. That year, SAMW in the east box was anomalously warm and salty (Figs. 6b,d). This positive $\theta$ anomaly was likely associated with the final phase of the weak El Niño in 2006/07, as positive $\theta$ anomalies in this region persisted over the time period 2006-08 (Figs. $6 \mathrm{~b}$ and $7 \mathrm{a}$ ).

In contrast, SAMW in the west box was anomalously cold in 2008 (Fig. 6a). Fogt and Barreira (2009) attributed the negative temperature anomaly in this region in 2008 to enhanced southerly winds in the eastern Ross Sea. The enhanced southerly winds also increased sea ice export from the eastern Ross Sea, so that subsequent melt contributed to a temperature decrease in the west box taking place during the entire year 2008, followed by a salinity decrease that started approximately six months later. Both anomalies subsequently propagated eastward (Fig. 7). As the negative $\theta$ anomaly coincided with a positive salinity anomaly (Figs. 6a,c), the density of CPSAMW in the west box overlapped with the density of SEPSAMW in the 

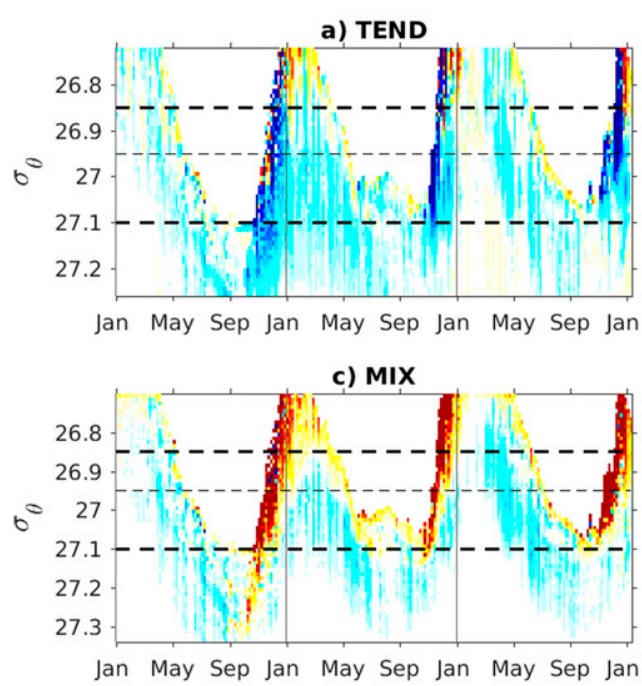

e) 10

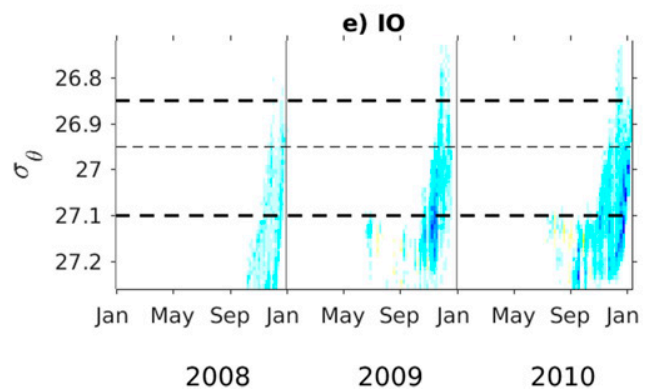

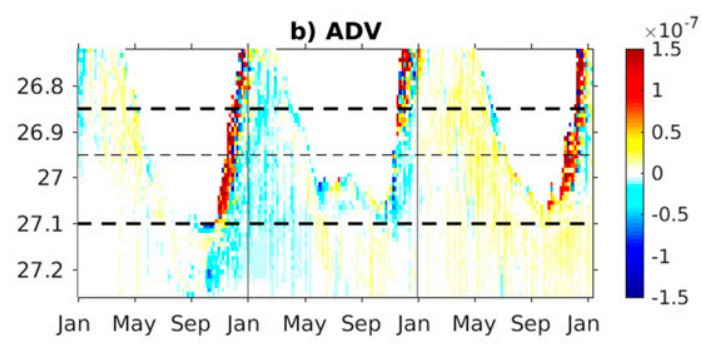
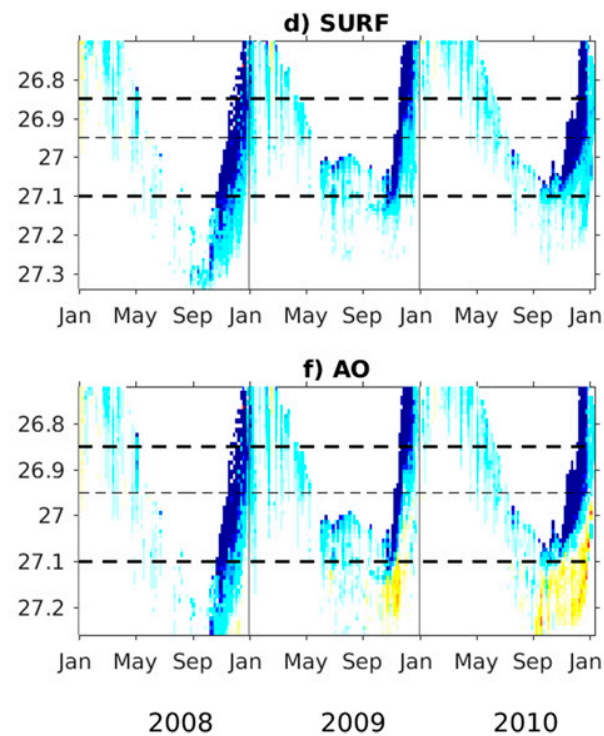

FIG. 10. The individual terms of SOSE salt budget given by Eq. (1), for years 2008-10, averaged over the region of strong freshening indicated by the red box in Figs. $8 \mathrm{c}-\mathrm{h}\left(124^{\circ}-85^{\circ} \mathrm{W}, 58^{\circ}-65.7^{\circ} \mathrm{S}\right)$, and binned into density bins $\sigma_{\theta}=0.01 \mathrm{~kg} \mathrm{~m}^{-3}$ wide. The budget was diagnosed in a form $\partial S / \partial t=-\nabla \cdot(\mathbf{u} S)+\kappa_{h} \nabla_{h}^{2} \mathrm{~S}+\partial_{z}\left[\kappa_{v}\left(\partial_{z} S-\gamma_{S}^{t}\right)\right]+$ $S \partial_{z}(E-P-R-\mathrm{IO})$, denoted as TEND $=\mathrm{ADV}+\mathrm{MIX}+\mathrm{SURF}\left(\mathrm{psu} \mathrm{s}^{-1}\right)$, so that positive values indicate salinity increase. Vertical thin lines show the beginning of each year. Surface forcing was further decomposed into sea iceocean component (IO) and atmosphere-ocean component (AO). Heavy horizontal dashed lines indicate limits of the SAMW density range $\sigma_{\theta}=26.85-27.1 \mathrm{~kg} \mathrm{~m}^{-3}$, and the thin horizontal dashed line shows density $\sigma_{\theta}=26.95 \mathrm{~kg} \mathrm{~m}^{-3}$ that separates the density range of CPSAMW (in the western box) and SEPSAMW (in the eastern box).

eastern box in 2008 much more than in any other year considered (Fig. 4b). Although negative $\theta$ anomaly in the west box was even stronger in 2010 than in 2008, it coincided with a very strong negative salinity anomaly (Figs. 6a,c), so that CPSAMW density in the west box was not as anomalously high in 2010 as it was in 2008 (Fig. 4b).

Maps of surface formation rate estimates in the SEPSAMW potential density range $\left(\sigma_{\theta}=26.95-\right.$ $27.1 \mathrm{~kg} \mathrm{~m}^{-3}$ ) obtained from Walin analysis using ERAInterim and RG09 Argo fields show strong formation in 2008 in the SEPSAMW density class over a broad longitudinal range that encompasses the location of both SAMW low-PV pools (Fig. 11d).

\section{Particle release experiment}

We use a particle release experiment to further investigate whether the enhanced sea ice melt that is a result of enhanced sea ice export from the east Ross Sea in 2008-10 could have caused the freshening observed in 2008-10 in the SEPSAMW density range (Figs. 6 and 7). We examine pathways and travel times of modeled particles released at the sea surface in each latitudelongitude SOSE model grid box in which the archived 5-day averaged salt flux by sea ice processes indicated freshening by sea ice melt. In the text that follows we consider particles released in 2008 that arrived north of the SAF into the longitude range of the SEPSAMW low-PV pool (Fig. A1) within three years following release. Considering all of the particles released in 2008, within three years after release $14 \%$ of particles arrive in the SEPSAMW formation region. The most traveled pathways of these particles are represented by the highest percentages of particles that visited each $1^{\circ}$ latitude $\times 1^{\circ}$ longitude box at any time within the next three years. 

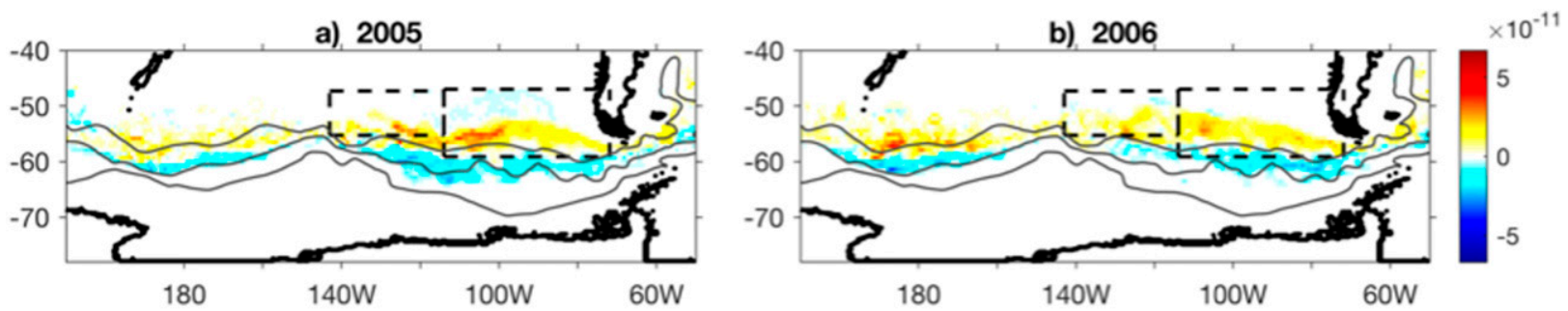

c) 2007
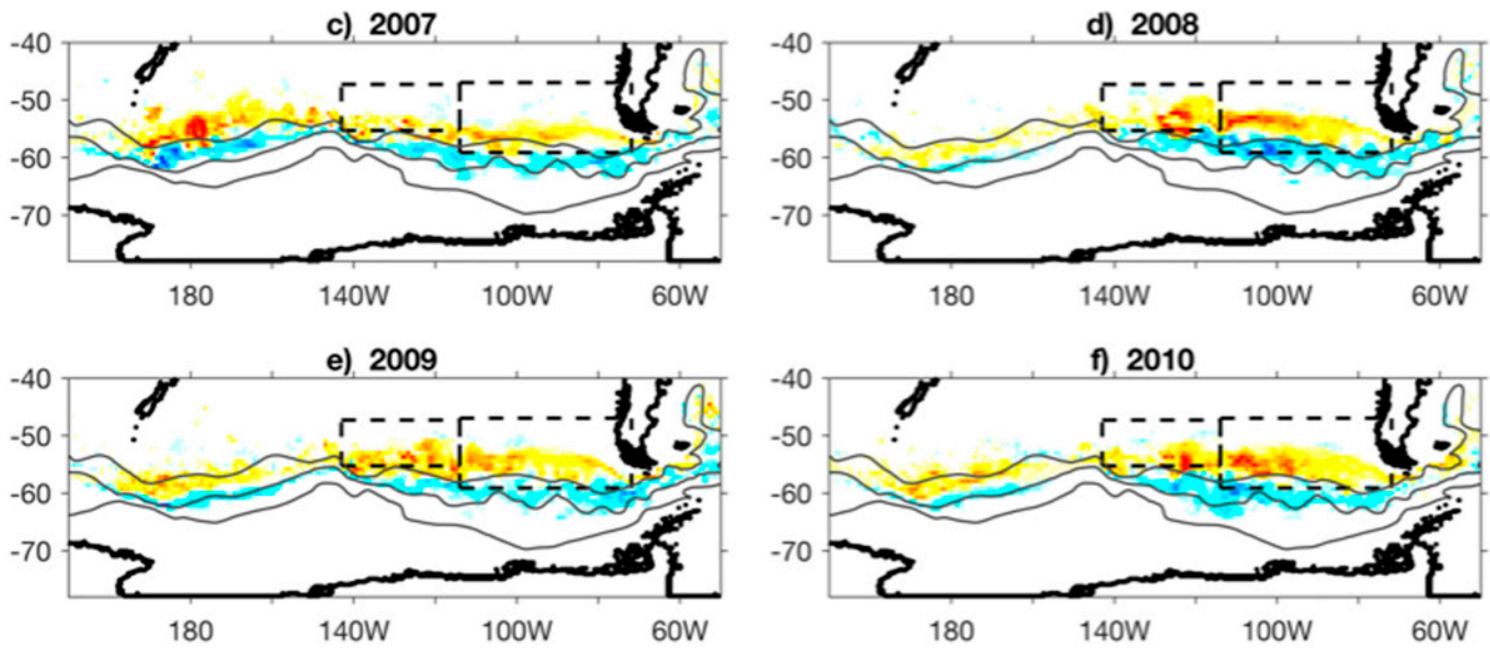

FIG. 11. Maps of austral winter (JAS) formation rate estimates per unit area by surface air-sea buoyancy flux, obtained from Walin analysis using daily averaged net air-sea heat flux, SST and $E-P$ from ERA-Interim reanalysis, combined with monthly averaged salinity (interpolated to daily values) from the uppermost layer (2.5-m depth), computed using the RG09 Argo product as the input field, for the years 2005-10. Formation rate estimates per unit area in the SEPSAMW potential density range $\sigma_{\theta}=26.95-27.10 \mathrm{~kg} \mathrm{~m}^{-3}$ were obtained from transformation rate estimates given by Eq. (4) binned in potential density bins of width $0.05 \mathrm{~kg} \mathrm{~m}^{-3}$. Black dashed lines show western and eastern SAMW boxes.

Dominant particle pathways are along the western side of the Pacific Antarctic Ridge and downstream (southeast) of the ridge, following the fronts of the ACC (Fig. 12a). This suggests that, in addition to northward Ekman transport, enhanced cross-frontal exchange associated with topography may be an important process for particles moving northward across the ACC fronts, in agreement with previous work (e.g., Thompson and Sallée 2012; Dufour et al. 2015; Tamsitt et al. 2017).

Of all the particles that reach the SEPSAMW formation region, particles tend to originate along the seasonal maximum sea ice extent and immediately poleward of it. In total, $96 \%$ of particles originate in the longitude range from $150^{\circ} \mathrm{E}$ to $120^{\circ} \mathrm{W}$, extending from slightly west of the Ross Sea to the eastern edge of the Amundsen Sea, with the majority of particles originating in the Ross Sea sector (Figs. 12b,c). None of the particles released farther west managed to cross the ACC fronts in the SEPSAMW sector in less than three years, whereas those particles that were released farther east were swept eastward through the Drake Passage without crossing the ACC fronts.
When they cross the SAF in the longitude range of the SEPSAMW low-PV pool, particles stay within the upper $20 \mathrm{~m}$ (Fig. 13c), supporting the idea that although particle pathways closely follow the topographically steered ACC fronts, in the region of strong freshwater input northward Ekman transport also plays an important role.

A probability density function of the start time of particles that eventually reach the SEPSAMW longitude range north of the SAF shows that most of the particles start out in austral spring/early summer 2008 when sea ice melt is strongest (Fig. 13a). This suggests that the location of particle release may be the dominant control, as it changes greatly through the year, while the seasonal variability of the advective times of particles, caused by seasonal variability of surface current speeds, is not so strong.

Particles released at the locations of sea ice melt in 2008 reach the SEPSAMW formation region one to two years after release (Fig. 13b); the mean arrival time is 550 days after the release, with a peak at 495 days and $20 \%$ of the particles reaching the SAF within a year of 


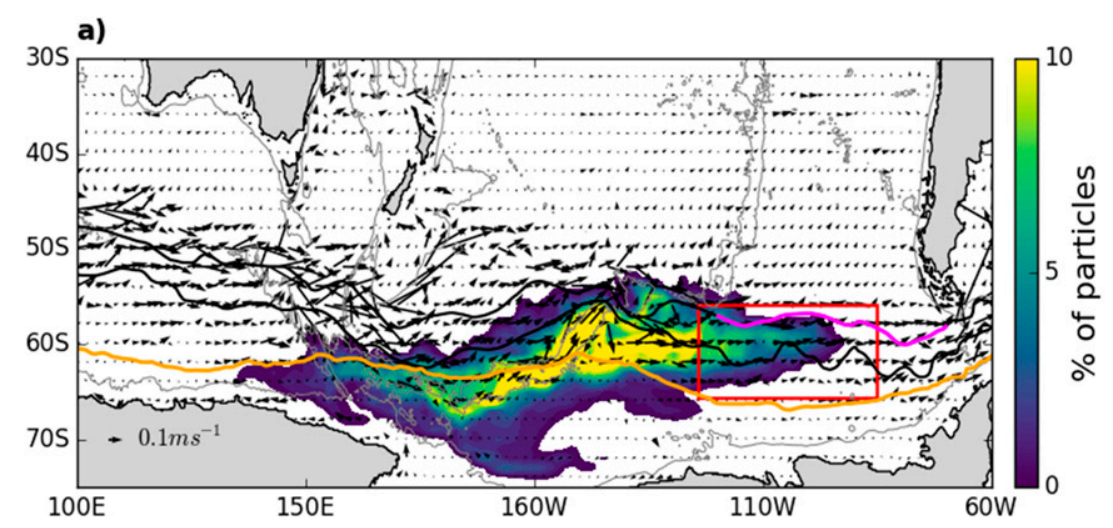

b)

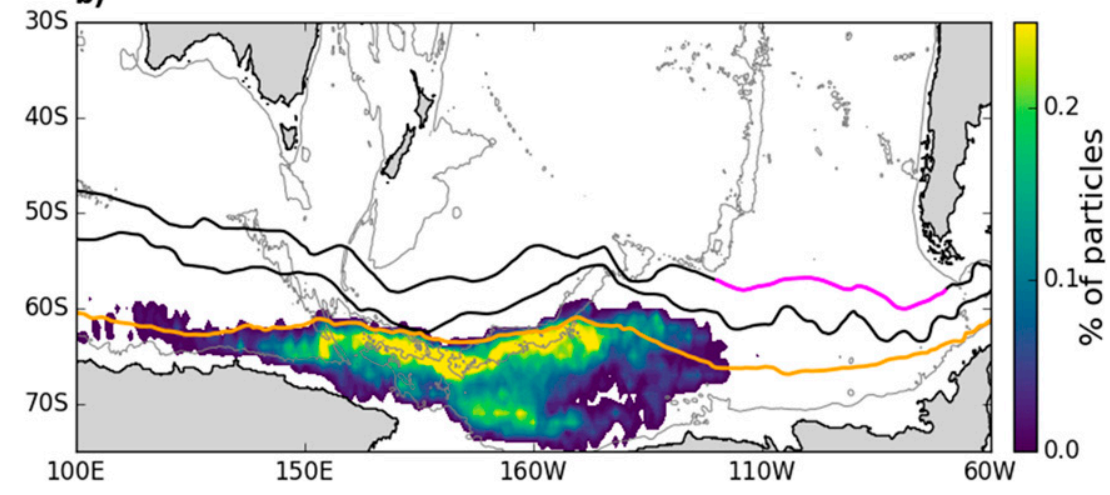

c)

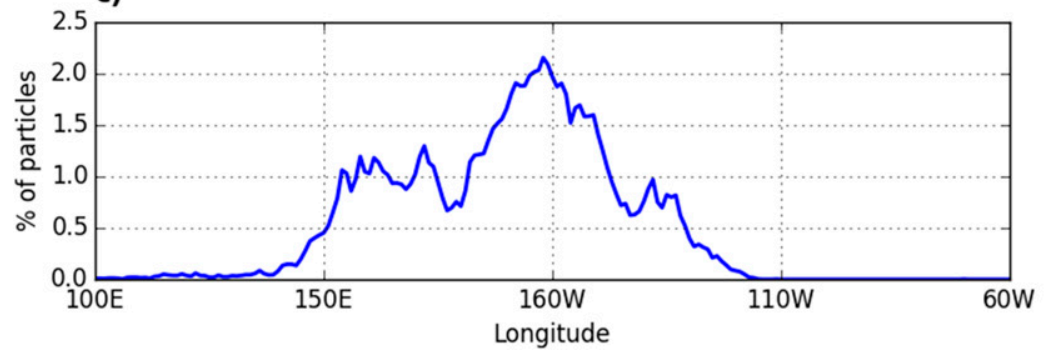

FIG. 12. The results of particle release experiment, considering only particles that travel north of Orsi et al's (1995) climatological SAF in the longitude range of the SEPSAMW lowPV pool (magenta contour). Particles have been weighted by melt rate at the time of their release. (a) Particle pathways shown as percentage of particles visiting each $1^{\circ}$ latitude $\times 1^{\circ}$ longitude water column at any time in the three years after their release in 2008. This means that in each $1^{\circ}$ latitude $\times 1^{\circ}$ longitude box the percentage of particles passing through can hypothetically range from $0 \%$ to $100 \%$. Particles were released in 2008 from locations of sea ice melt, determined from the SOSE 5-day averaged sea ice freshwater flux. The orange line shows the monthly mean September Antarctic sea ice extent, defined by $15 \%$ concentration. Black arrows show the SOSE 2005-10 mean surface velocity vectors. (b) The initial release locations of particles whose pathways are shown in (a), also weighted by the ice-ocean freshwater flux. (c) Longitudinal distribution of release points for particles that travel north of the SAF. The black contours in (a) and (b) indicate climatological positions of the SAF and PF given by Orsi et al. (1995), and the magenta line shows where the particles cross the SAF within the longitude range of the SEPSAMW low-PV pool (shown in Fig. A1). The red box, as in Fig. $8,124^{\circ}-85^{\circ} \mathrm{W}$, $58^{\circ}-65.7^{\circ} \mathrm{S}$ indicates the location of strongest freshening.

release. This suggests that strong sea ice export from the Ross Sea, and subsequent sea ice melt can play an important role in the freshening of SEPSAMW in the subsequent two years.
We have additionally compared the particle pathways calculated with and without adding weights to the particles on the basis of the melt rate at the release location, but found that this weighting did not significantly change 

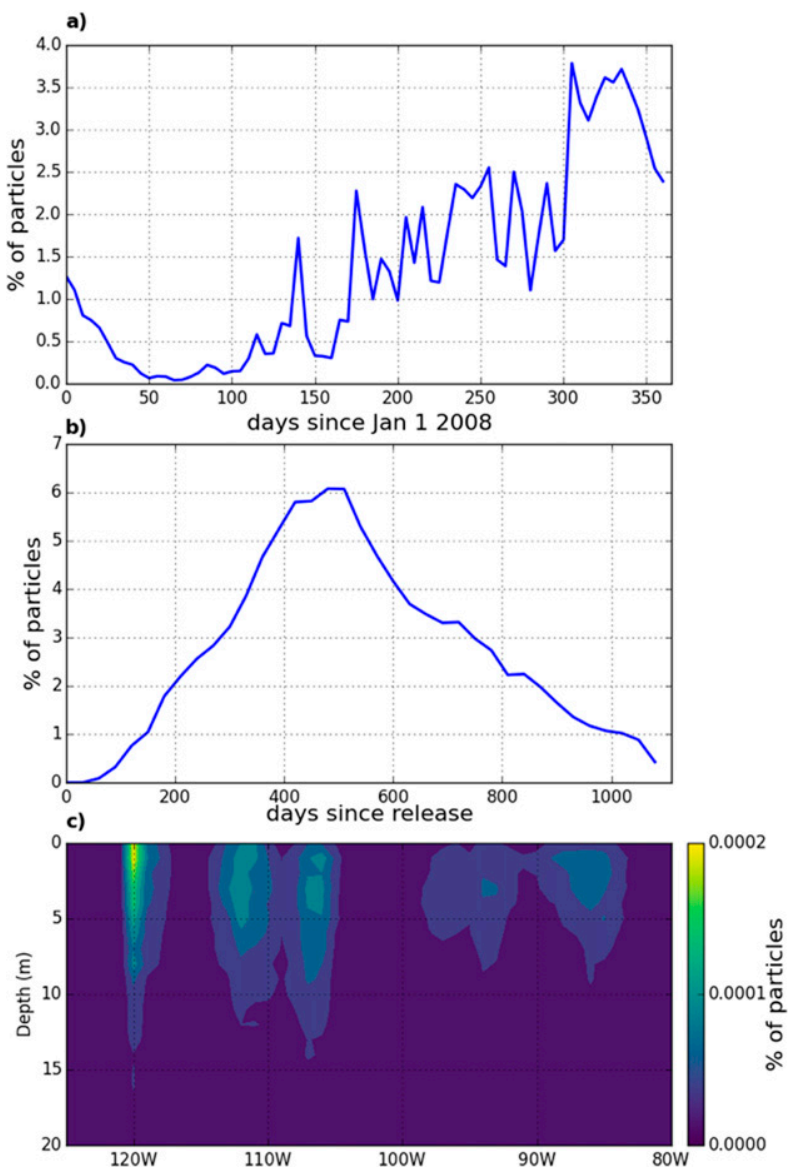

FIG. 13. (a) Time of release of particles, with pathways shown in Fig. 12, expressed in days after 1 Jan 2008, (b) time since release (in days) to first crossing of the SAF, at some time during the three years after particle release, and (c) depth-longitude distribution of location where particles, with pathways shown in Fig. 12a, reach the $\mathrm{SAF}$, at the time of crossing.

the results presented in Fig. 13 (not shown). This implies that the pathways are robust, and the melt rate itself has minimal impact on the flow. Thus the location of the injection plays an important role, and not its rate.

\section{Discussion and conclusions}

We have analyzed cooling and freshening in the highlatitude (south of $50^{\circ} \mathrm{S}$ ) southeast Pacific in the years 2008-10, using SOSE, the RG09 Argo product of Roemmich and Gilson (2009), and our own qualitycontrolled dataset of Argo profiles, together with their mapping to a regular grid. The SOSE results have been verified against the observations and other observationally based products, because SOSE iteration 100 builds upon two separate SOSE optimizations with different atmospheric constraints for the atmospheric variables utilized to optimize the simulation; for the years $2005-07$, constraints were based on the NCEPNCAR Reanalysis 1 (Kalnay et al. 1996), and for the years 2008-10 they were based on the ERA-Interim reanalysis (Dee et al. 2011).

In 2008 and 2010, the ASL was anomalously deep and located farther east than in 2005-07 (Fig. 2). Such conditions strengthened southerly winds in the eastern Ross Sea and Amundsen Sea, driving stronger northward sea ice export. Together with strong zonal winds along the ACC, this caused the sea ice edge to extend farther north and east than in 2005-07. Thus, in austral spring 2008, an anomalously large amount of sea ice was present at the northward extent of the Amundsen Sea. Melting of this ice introduced negative salinity and potential temperature anomalies that were advected eastward and mixed over the next two years and over a wide depth range. The intrusion of a negative salinity anomaly equatorward of the ACC was evident not only in the AAIW, but also in the lighter SEPSAMW density range. The strongest freshening of SEPSAMW was east of the Pacific-Antarctic ridge. Strengthened southerly winds decreased temperature in the CPSAMW region in 2008, increasing its density, so that in 2008 it largely overlapped with that of the SEPSAMW, resulting in two modes of SEPSAMW; one in the west that was cold and fresh, while the second, located in SEPSAMW region, was warm and salty. The positive temperature anomaly of this eastern mode in 2008 was likely associated with the closing phase of the 2006/07 El Niño (Fig. 9b) and the lag time in advection of the cool fresh anomaly from farther west.

A particle release experiment was used to investigate whether the strong sea ice export from the Ross Sea in 2008 , driven by the strong southerly winds, and its subsequent melt, could have played an important role in the observed freshening of SAMW in the years 2009 and 2010 (Figs. 6 and 7). Particles were released at the location of sea ice melt determined from SOSE 5-day averaged sea ice freshwater flux. We considered only particles that reached the SAMW region north of the $\mathrm{SAF}$, in the longitude range $120^{\circ}-75^{\circ} \mathrm{W}$ within three years. Most of these particles originated in the Ross Sea longitude range, and the mean travel time of these particles was one to two years. This suggests that freshening by strong sea ice export from the eastern Ross Sea in 2008 could have played an important role in SAMW freshening in 2009 and 2010. This also implies that interannual large-scale climate fluctuations can affect SAMW at different time scales and via remote teleconnections. A strong SAM/ENSO/ASL event may drive local and near instantaneous changes via Ekman transport, deeper mixing, and heat flux changes, but it may also induce changes in sea ice concentration and melt distribution in upstream regions, which then take 
1-2 years to be advected to the SAMW region. This travel time for particles from the Ross Sea to reach the SAMW formation region suggests that there may be a time lag on the order of 1-2 years for anomalous ice melt rates to have the strongest impact on SEPSAMW formation. Further work could investigate both the importance of this time lag in the response of SEPSAMW formation to climate variability and how the timeintegrated response of SAMW properties may be best mapped onto climate modes but is beyond the scope of this current work.

The atmospheric, oceanic, and cryosphere conditions in the South Pacific in 2008 were similar to the conditions in 1998, when a strong +SAM coincided with a -ENSO, and strengthened zonal winds triggered a transitory shift to an Ekman-dominated mode of SAMW ventilation in southeast Pacific, resulting in the formation of two varieties of SAMW: a southern mode that was cold and fresh and a northern mode that was warm and salty (NG09). NG09 have attributed the northern warm and salty mode to the closing phase of the pronounced $1997 / 98$ El Niño. It is thus likely that for the development of the two modes of SAMW, it is necessary that combined +SAM and -ENSO conditions follow + ENSO in order for a warm and salty mode to be present at the same time as a cold and fresh one.

NG09 further showed a 1-2-yr shutdown of AAIW formation in the Drake Passage region after 1998, when the two modes of SAMW were formed. Our results raise the possibility that the shutdown of AAIW formation could partly be caused by destruction of water in the AAIW density range that is transformed into the SAMW density range by strong surface freshening. It is also possible that due to strong freshening in the region, sea ice meltwater entered the SAMW density range instead of entering the AAIW density range.

Our results are also relevant for decadal variability in the Southern Ocean. The SAM is the dominant mode of climate variability in the extratropical Southern Hemisphere on interannual time scales, and changes in the SAM drive variations of the deep Southern Ocean mixed layers associated with SAMW formation (Sallée et al. 2010a). The SAM showed a quasi-decadal variability with predominantly negative phases in the 1960s and 1980s and positive phases in the 1990s (Yuan and Yonekura 2011). These decadal changes might be linked to an intensified high-latitude atmospheric response to ENSO in the 1990s in association with increased covariability between ENSO and SAM (Fogt and Bromwich 2006), as in the last 50 years there was a tendency for La Niña events to occur with a +SAM and El Niño events with -SAM, strengthening the teleconnection with the southeast Pacific. In the high latitudes of the southeast Pacific, the sea ice response to SAM/ENSO variability is strongest when La Niña events coincide with a + SAM and when El Niño events coincide with a -SAM (Stammerjohn et al. 2008). A better understanding of the drivers and linkages between these decadal variations is required. We have not identified which climate mode is dominant, nor have we analyzed the relative role of different processes in interannual variability of SEPSAMW volume and properties.

We have shown that the interannual variability in sea ice export from the Ross Sea, which is tied to large-scale climate fluctuations, is likely to play a significant role in interannual variability of volume and properties not only of AAIW, but also of SAMW, at time scales up to two years. Given the fundamental role these water masses play in air-sea exchange, sequestration of carbon and heat, nutrient supply, and biological productivity, it is important that future work also consider the potential impact that changes in sea ice distribution and thickness may have on these properties.

Acknowledgments. We thank three anonymous reviewers whose insightful, motivating comments greatly improved the paper. IC, MRM, and STG were supported by the National Science Foundation (NSF) Ocean Sciences Grant NSF OCE-1658001 to Scripps Institution of Oceanography. Additional funding came from Grants NSF PLR-1425989, NSF OCE-1234473, and NSF OCE-1357072, which also supported VT. AJSM was supported by Natural Environment Research Council (NERC) Grant NE/N018095/1 (Ocean Regulation of Climate by Heat and Carbon Sequestration and Transports; ORCHESTRA). SOSE was produced using the Extreme Science and Engineering Discovery Environment (XSEDE), which is supported by the NSF Grant MCA06N007. The SOSE output used in this study can be found at sose.ucsd.edu. The objectively mapped Argo data were provided by John Gilson, available from http://www.argo.ucsd.edu/Gridded fields.html. Argo data were collected and made freely available by the International Argo Program and the national programs that contribute to it (http://www.argo. ucsd.edu; http://argo.jcommops.org; http://doi.org/10.17882/ 42182). The Argo Program is part of the Global Ocean Observing System. The ERA-Interim dataset, developed by the European Centre for Medium-Range Weather Forecasts, was obtained from the Research Data Archive at the National Center for Atmospheric Research, Computational and Information Systems Laboratory: http://rda.ucar.edu/datasets/ds627.0/. The code used for the Lagrangian experiment is available from https://github.com/jinbow/Octopus. The ASL index was obtained from https://climatedataguide.ucar. edu/climate-data/amundsen-sea-low-indices. 

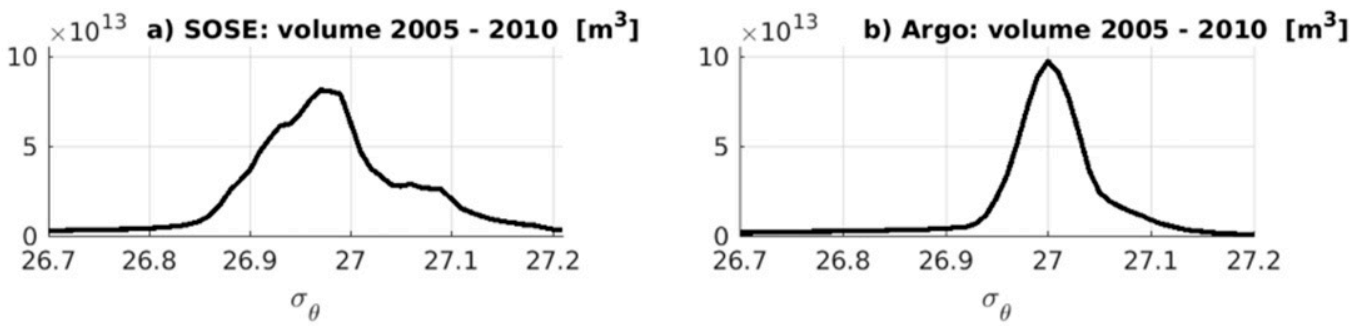

c) Thickness: $2005-2010[\mathrm{~m}]$

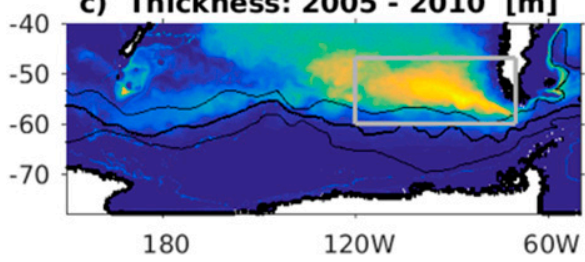

d) Thickness: $2005-2010[\mathrm{~m}]$

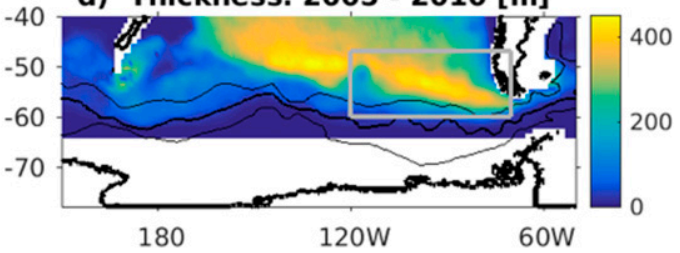

FIG. A1. Time averaged over years $2005-10,(\mathrm{a}),(\mathrm{b})$ the volume of water $\left(\mathrm{m}^{3}\right)$ with $\mathrm{PV}<40 \times 10^{-12} \mathrm{~m}^{-1} \mathrm{~s}^{-1}$, in the region of the SAMW low-PV pool $\left(120^{\circ}-75^{\circ} \mathrm{W}, 47^{\circ}-60^{\circ} \mathrm{S}\right)$, shown as a gray box in (c) and (d), and (c),(d) thickness of water $(\mathrm{m})$ in the SAMW density range $\sigma_{\theta}=26.85-27.1 \mathrm{~kg} \mathrm{~m}^{-3}$ with $\mathrm{PV}<40 \times 10^{-12} \mathrm{~m}^{-1} \mathrm{~s}^{-1}$. Quantities are calculated using monthly mean (left) SOSE $\theta$ and $S$ interpolated onto the vertical grid of the Argo product, and (right) $T$ and $S$ from the RG09 Argo product, both binned into potential density bins of width $0.01 \mathrm{~kg} \mathrm{~m}^{-3}$. The black contours indicate climatological positions of the fronts given by Orsi et al. (1995), from north to south: SAF, PF, and SACCF.

\section{APPENDIX}

\section{Validation of SOSE Iteration 100 for 2005-10 in the Southeast Pacific}

We provide here a brief validation of SOSE iteration 100 for 2005-10 in the southeast Pacific, the region analyzed in this work. We first determine the density of low potential vorticity SAMW in the RG09 Argo product and in SOSE by estimating the volume of water in individual potential density layers that are $0.01 \mathrm{~kg} \mathrm{~m}^{-3}$ wide and that satisfy a low potential vorticity constraint $\left(\mathrm{PV}<40 \times 10^{-12} \mathrm{~m}^{-1} \mathrm{~s}^{-1}\right)$. We consider a region $120^{\circ}-$ $75^{\circ} \mathrm{W}, 47^{\circ}-60^{\circ} \mathrm{S}$, which encompasses the SAMW low-PV pools (Figs. A1c,d).

In both the Argo product and in SOSE the volume maximum of low-PV water, which corresponds to the core of SEPSAMW, is centered very close to $\sigma_{\theta}=$ $27.0 \mathrm{~kg} \mathrm{~m}^{-3}$ (Figs. A1a,b). This agrees well with estimates from the other SOSE iterations $\left[\sigma_{\theta}=27.0 \mathrm{~kg} \mathrm{~m}^{-3}\right.$ in both Cerovečki et al. (2013) and Cerovečki and Mazloff (2016)], as well as with estimates from the

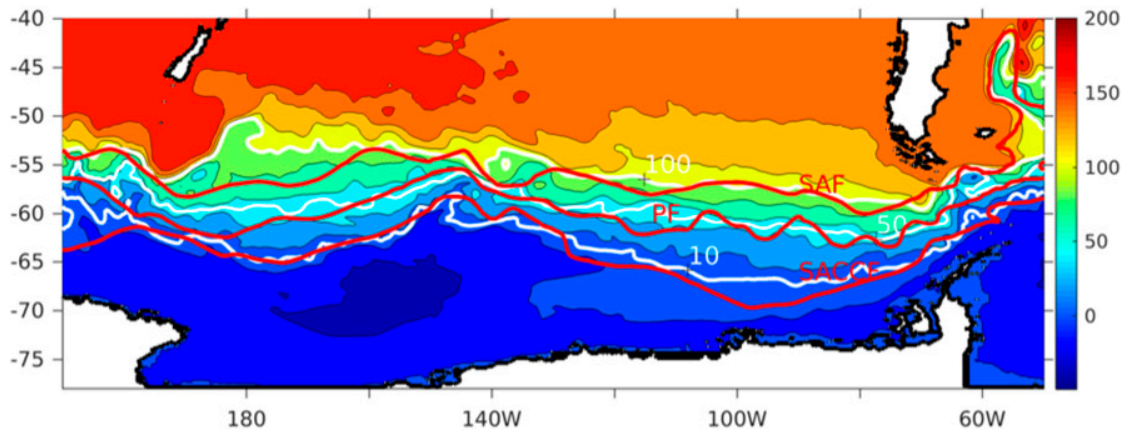

FIG. A2. Time averaged 2005-10 vertically integrated transport streamfunction from SOSE (shown in colors), shown with a 20-Sv contour interval, together with (in white) selected contour levels $(10,50$, and $100 \mathrm{~Sv})$ that tend to align with (in red) the climatological positions of the fronts given by Orsi et al. (1995), from north to south: SAF, PF, and SACCF. 

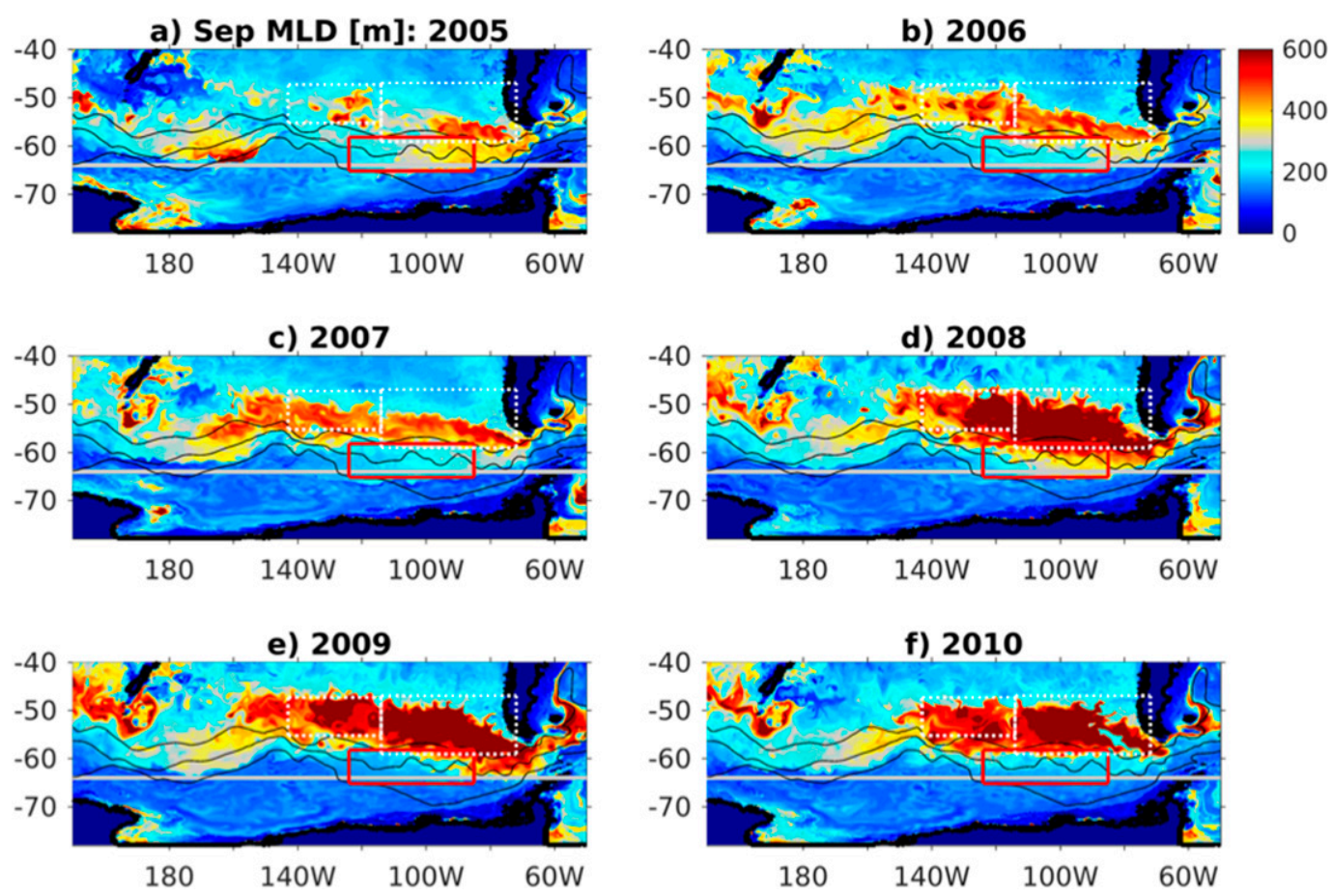

FIG. A3. As in Fig. 3, except using SOSE output that has been averaged to monthly means and vertically interpolated to the Argo vertical grid.

hydrography (e.g., $\sigma_{\theta}=27.05-27.15 \mathrm{~kg} \mathrm{~m}^{-3}$; Talley et al. 2011). Although the density of the volume maximum in SOSE is very close to that of the Argo product, the volume of low-PV water in SOSE is distributed over a wider isopycnal range than in the Argo product (Figs. A1a, b). We define the SEPSAMW density range to be $\sigma_{\theta}=$ 26.95-27.1 $\mathrm{kg} \mathrm{m}^{-3}$, but for both SOSE and Argo the results of our analysis are sensitive neither to small changes in the density range that defines SEPSAMW nor to small changes in the analysis region considered.

Time-mean positions of major ACC fronts in SOSE have been compared with the climatological position of the Orsi et al. (1995) fronts. While overall the time-averaged 2005-10 vertically integrated transport streamfunction from SOSE aligns well with the climatological positions of the fronts given by Orsi et al. (1995) in the southeast Pacific, there are also some discrepancies (e.g., for the SAF around $180^{\circ}$; Fig. A2). While identifying the source of discrepancies is beyond the scope of this paper, we note that they may result from differing frontal definitions or from the rather limited number of available hydrographic sections on which the Orsi et al. (1995) fronts are based. (Fig. A2).

Comparison of September monthly mean mixed layer depths from the RG09 Argo product (Fig. 3) and from SOSE (Fig. A3) suggests that in the years 2005-07, SOSE tends to underestimate the depth of winter mixed layers, while in the years 2008-10, SOSE tends to overestimate the depth of winter mixed layers.

\section{REFERENCES}

Abernathey, R. P., I. Cerovecki, P. Holland, E. Newsom, M. Mazloff, and L. D. Talley, 2016: Water mass transformation by sea ice in the upper branch of the Southern Ocean overturning. Nat. Geosci., 9, 596-601, https://doi.org/10.1038/ngeo2749.

Aoki, S., S. R. Rintoul, S. Ushio, S. Watanabe, and N. L. Bindoff, 2005: Freshening of the Adelie Land Bottom Water near $140^{\circ}$ E. Geophys. Res. Lett., 32, L23601, https://doi.org/10.1029/ 2005 GL024246.

— M. Hariyama, H. Mitsudera, H. Sasaki, and Y. Sasai, 2007: Formation regions of Subantarctic Mode Water detected by OFES and Argo profiling floats. Geophys. Res. Lett., 34, L10606, https://doi.org/10.1029/2007GL029828.

Ballarotta, M., S. Drijfhout, T. Kuhlbrodt, and K. Döös, 2013: The residual circulation of the Southern Ocean: Which spatiotemporal scales are needed? Ocean Modell., 64, 46-55, https:// doi.org/10.1016/j.ocemod.2013.01.005.

Carril, A. F., and A. Navarra, 2001: Low-frequency variability of the Antarctic Circumpolar Wave. Geophys. Res. Lett., 28, 4623-4626, https://doi.org/10.1029/2001GL013804.

Cerovečki, I., and J. Marshall, 2008: Eddy modulation of air-sea interaction and convection. J. Phys. Oceanogr., 38, 65-83, https://doi.org/10.1175/2007JPO3545.1.

_ , and M. R. Mazloff, 2016: The spatiotemporal structure of diabatic processes governing the evolution of Subantarctic Mode Water in the Southern Ocean. J. Phys. Oceanogr., 46, 683-710, https://doi.org/10.1175/JPO-D-14-0243.1. 
_ L. Talley, M. Mazloff, and G. Maze, 2013: Subantarctic Mode Water formation in eddy-permitting Southern Ocean State Estimate. J. Phys. Oceanogr., 43, 1485-1511, https://doi.org/ 10.1175/JPO-D-12-0121.1.

Chung, M. V., I. Cerovecki, M. R. Mazloff, S. Gille and L. D. Talley, 2018: Variability of sea ice production in the Ross Sea from 2006-2010 and its relationship to the Amundsen Sea low. 2018 Ocean Sciences Meeting, Portland, OR, Amer. Geophys. Union, Abstract HE44C3005.

Close, S. E., A. C. Naveira Garabato, E. L. McDonagh, B. A. King, M. Biuw, and L. Boehme, 2013: Control of Mode and Intermediate Water mass properties in Drake Passage by the Amundsen Sea low. J. Climate, 26, 5102-5123, https://doi.org/ 10.1175/JCLI-D-12-00346.1.

Dee, D. P., and Coauthors, 2011: The ERA-Interim reanalysis: Configuration and performance of the data assimilation system. Quart. J. Roy. Meteor. Soc., 137, 553-597, https://doi.org/ 10.1002/qj.828.

Desbruyères, D. G., S. Purkey, G. J. Johnson, E. L. McDonagh, and B. A. King, 2016: Deep and abyssal ocean warming from 35 years of repeat hydrography. Geophys. Res. Lett., 43, 1035610 365, https://doi.org/10.1002/2016GL070413.

Dong, S., S. L. Garzoli, and M. Baringer, 2009: An assessment of the seasonal mixed layer salinity budget in the Southern Ocean. J. Geophys. Res., 114, C12001, https://doi.org/10.1029/ 2008JC005258.

Dufour, C. O., and Coauthors, 2015: Role of mesoscale eddies in cross-frontal transport of heat and biogeochemical tracers in the Southern Ocean. J. Phys. Oceanogr., 45, 3057-3081, https://doi.org/10.1175/JPO-D-14-0240.1.

Durack, P. J., S. E. Wijffels, and R. J. Matear, 2012: Ocean salinities reveal strong global water cycle intensification during 1950 to 2000. Science, 336, 455-458, https://doi.org/10.1126/ science. 1212222

Fogt, R. L., and D. H. Bromwich, 2006: Decadal variability of the ENSO teleconnection to the high-latitude South Pacific governed by coupling with the southern annular mode. J. Climate, 19, 979-997, https://doi.org/10.1175/JCLI3671.1.

_ , and S. Barreira, 2009: [Antarctica] Atmospheric circulation [in "State of the Climate in 2008"]. Bull. Amer. Meteor. Soc., 90 (8), S114-S116, https://doi.org/10.1175/BAMS-908-StateoftheClimate.

Garrett, C., and A. Tandon, 1997: The effects on water mass formation of surface mixed layer time-dependence and entrainment fluxes. Deep-Sea Res., 44, 1991-2006, https://doi.org/ 10.1016/S0967-0637(97)00055-1.

— , K. Speer, and E. Tragou, 1995: The relationship between water mass formation and the surface buoyancy flux, with application to Phillips' Red Sea model. J. Phys. Oceanogr., 25, 1696-1705, https://doi.org/10.1175/1520-0485(1995)025<1696: TRBWMF $>2.0 . \mathrm{CO} ; 2$

Gille, S. T., 2008: Decadal-scale temperature trends in the Southern Hemisphere ocean. J. Climate, 21, 4749-4765, https:// doi.org/10.1175/2008JCLI2131.1.

Hallberg, R., 2013: Using a resolution function to regulate parameterizations of oceanic mesoscale eddy effects. Ocean Modell., 72, 92-103, https://doi.org/10.1016/j.ocemod.2013.08.007.

Hanawa, K., and L. D. Talley, 2001: Mode waters. Ocean Circulation and Climate, G. Siedler, J. Church, and J. Gould, Eds. International Geophysics Series, Vol. 77, Academic Press, 373-386.

Hartin, C. A., R. A. Fine, B. M. Sloyan, L. D. Talley, T. K. Chereskin, and J. Happell, 2011: Formation rates of Subantarctic Mode
Water and Antarctic Intermediate Water within the South Pacific. Deep-Sea Res. I, 58, 524-534, https://doi.org/10.1016/ j.dsr.2011.02.010.

Haumann, F. A., D. Notz, and H. Schmidt, 2014: Anthropogenic influence on recent circulation-driven Antarctic sea-ice changes. Geophys. Res. Lett., 41, 8429-8437, https://doi.org/ 10.1002/2014GL061659.

, N. Gruber, M. Münnich, I. Frenger, and S. Kern, 2016: Sea ice transport driving Southern Ocean salinity and its recent trends. Nature, 537, 89-92, https://doi.org/10.1038/nature19101.

Herraiz-Borreguero, L., and S. Rintoul, 2011: Subantarctic Mode Water: Distribution and circulation. Ocean Dyn., 61, 103-126, https://doi.org/10.1007/s10236-010-0352-9.

Holland, P. R., and R. Kwok, 2012: Wind-driven trends in Antarctic sea-ice drift. Nat. Geosci., 5, 872-875, https://doi.org/ 10.1038/ngeo1627.

- , and N. Kimura, 2016: Observed concentration budgets of Arctic and Antarctic sea ice. J. Climate, 29, 5241-5249. https:// doi.org/10.1175/JCLI-D-16-0121.1.

- , N. Bruneau, C. Enright, N. T. Kurtz, M. Losch and R. Kwok, 2014: Modelled trends in Antarctic sea ice thickness. J. Climate, 27, 3784-3801, https://doi.org/10.1175/JCLI-D-1300301.1.

Holte, J. W., L. D. Talley, T. K. Chereskin, and B. M. Sloyan, 2013: Subantarctic mode water in the southeast Pacific: Effect of exchange across the Subantarctic Front. J. Geophys. Res., 118, 2052-2066, https://doi.org/10.1002/jgrc.20144.

Hosking, J. S., A. Orr, T. J. Bracegirdle, and J. Turner, 2016: Future circulation changes off West Antarctica: Sensitivity of the Amundsen Sea low to projected anthropogenic forcing. Geophys. Res. Lett., 43, 367-376, https://doi.org/10.1002/ 2015GL067143.

Ito, T., M. Woloszyn, and M. Mazloff, 2010: Anthropogenic carbon dioxide transport in the Southern Ocean driven by Ekman flow. Nature, 463, 80-83, https://doi.org/10.1038/nature08687.

Iudicone, D., G. Madec, and T. J. McDougall, 2008: Water-mass transformations in a neutral density framework and the key role of light penetration. J. Phys. Oceanogr., 38, 1357-1376, https://doi.org/10.1175/2007JPO3464.1

Jacobs, S. S., and C. F. Giulivi, 2010: Large multidecadal salinity trends near the Pacific-Antarctic continental margin. J. Climate, 23, 4508-4524, https://doi.org/10.1175/2010JCLI3284.1.

,-- , and P. A. Mele, 2002: Freshening of the Ross Sea during the late 20th century. Science, 297, 386-389, https://doi.org/ 10.1126/science. 1069574

Jones, D. C., A. J. S. Meijers, E. Shuckburgh, J.-B. Sallée, P. Haynes, E. Karczewska, and M. R. Mazloff, 2016: How does Subantarctic Mode Water ventilate the Southern Hemisphere subtropics? J. Geophys. Res. Oceans., 121, 6558-6582, https:// doi.org/10.1002/2016JC011680.

Kalnay, E., and Coauthors, 1996: The NCEP/NCAR 40-Year Reanalysis Project. Bull. Amer. Meteor. Soc., 77, 437-471, https:// doi.org/10.1175/1520-0477(1996)077<0437:TNYRP>2.0.CO;2.

Landschützer, P., and Coauthors, 2015: The reinvigoration of the Southern Ocean carbon sink. Science, 349, 1221-1224, https:// doi.org/10.1126/science.aab2620.

Large, W. G., J. C. McWilliams, and S. C. Doney, 1994: Oceanic vertical mixing: A review and a model with a vertical K-profile boundary layer parameterization. Rev. Geophys., 32, 363-403, https://doi.org/10.1029/94RG01872.

Marshall, G. J., 2003: Trends in the southern annular mode from observations and reanalyses. J. Climate, 16, 4134-4143, https:// doi.org/10.1175/1520-0442(2003)016<4134:TITSAM>2.0.CO;2. 
— shall Southern Annular Mode (SAM) Index (Station-based). https://climatedataguide.ucar.edu/climate-data/marshall-southernannular-mode-sam-index-station-based.

Marshall, J., D. Jamous, and J. Nilsson, 1999: Reconciling thermodynamic and dynamic methods of computation of watermass transformation rates. Deep-Sea Res., 46, 545-572, https:// doi.org/10.1016/S0967-0637(98)00082-X.

Masich, J., T. K. Chereskin, and M. R. Mazloff, 2015: Topographic form stress in the Southern Ocean State Estimate. J. Geophys. Res., 120, 7919-7933, https://doi.org/10.1002/ 2015JC011143.

Maze, G., G. Forget, M. Buckley, J. Marshall, and I. Cerovečki, 2009: Using transformation and formation maps to study the role of air-sea heat fluxes in North Atlantic eighteen degree water formation. J. Phys. Oceanogr., 39, 1818-1835, https:// doi.org/10.1175/2009JPO3985.1.

Mazloff, M. R., P. Heimbach, and C. Wunsch, 2010: An eddypermitting Southern Ocean State Estimate. J. Phys. Oceanogr., 40, 880-899, https://doi.org/10.1175/2009JPO4236.1.

McCartney, M. S., 1977: Subantarctic Mode Water. A Voyage of Discovery: George Deacon 70th Anniversary Volume, M. V. Angel, Ed., Pergamon Press, 103-119.

_ 1982: The subtropical recirculation of Mode Waters. J. Mar. Res., 40 (Suppl.), 427-464.

Meijers, A. J. S., N. L. Bindoff, and S. R. Rintoul, 2011: Frontal movements and property fluxes: Contributions to heat and freshwater trends in the Southern Ocean. J. Geophys. Res., 116, C08024, https://doi.org/10.1029/ 2010JC006832.

Molinelli, E. J., 1981: The Antarctic influence on Antarctic Intermediate Water. J. Mar. Res., 39, 267-293.

Naveira Garabato, A. C., L. Jullion, D. P. Stevens, K. J. Heywood, and B. A. King, 2009: Variability of Subantarctic Mode Water and Antarctic Intermediate Water in the Drake Passage during the late-twentieth and early-twenty-first centuries. J. Climate, 22, 3661-3688, https://doi.org/10.1175/ 2009JCLI2621.1.

Nurser, A. J. G., R. Marsh, and R. G. Williams, 1999: Diagnosing water mass formation from air-sea fluxes and surface mixing. J. Phys. Oceanogr., 29, 1468-1487, https://doi.org/10.1175/ 1520-0485(1999)029<1468:DWMFFA > 2.0.CO;2.

Orsi, A. H., T. Whitworth III, and W. D. Nowlin Jr., 1995: On the meridional extent and fronts of the Antarctic Circumpolar Current. Deep-Sea Res., 42, 641-673, https://doi.org/10.1016/ 0967-0637(95)00021-W.

Paolo, F. S., H. A. Fricker, and L. Padman, 2015: Volume loss from Antarctic ice shelves is accelerating. Science, 348, 327-331, https://doi.org/10.1126/science.aaa0940.

Purkey, S. G., and G. C. Johnson, 2013: Antarctic Bottom Water warming and freshening: Contributions to sea level rise, ocean freshwater budgets, and global heat gain. J. Climate, 26, 61056122, https://doi.org/10.1175/JCLI-D-12-00834.1.

Raphael, M. N., and Coauthors, 2016: The Amundsen Sea low: Variability, change, and impact on Antarctic climate. Bull. Amer. Meteor. Soc., 97, 111-121, https://doi.org/10.1175/ BAMS-D-14-00018.1.

Roemmich, D., and J. Gilson, 2009: The 2004-2008 mean and annual cycle of temperature, salinity, and steric height in the global ocean from the Argo Program. Prog. Oceanogr., 82, 81100, https://doi.org/10.1016/j.pocean.2009.03.004.

- J. Church, J. Gilson, D. Monselesan, P. Sutton, and S. Wijffels, 2015: Unabated planetary warming and its ocean structure since 2006. Nat. Climate Change, 5, 240-245, https:// doi.org/10.1038/nclimate2513.

Sabine, C. L., and Coauthors, 2004: The oceanic sink for anthropogenic $\mathrm{CO}_{2}$. Science, 305, 367-371, https://doi.org/10.1126/ science.1097403.

Saenko, O. A., and A. J. Weaver, 2001: Importance of wind-driven sea ice motion for the formation of Antarctic Intermediate Water in a global climate model. Geophys. Res. Lett., 28, 41474150, https://doi.org/10.1029/2001GL013632.

Sallée, J. B., K. Speer, and S. Rintoul, 2010a: Zonally asymmetric response of the Southern Ocean mixed-layer depth to the southern annular mode. Nat. Geosci., 3, 273-279, https:// doi.org/10.1038/ngeo812.

,,--- , and S. Wijffels, 2010b: Southern Ocean thermocline ventilation. J. Phys. Oceanogr., 40, 509-529, https:// doi.org/10.1175/2009JPO4291.1.

Sarmiento, J. L., N. Gruber, M. A. Brzezinski, and J. P. Dunne, 2004: High-latitude controls of thermocline nutrients and low latitude biological productivity. Nature, 427, 56-60, https:// doi.org/10.1038/nature02127.

Schmitz, W. J., 1996: On the World Ocean circulation. Vol. II: The Pacific and Indian Oceans-A global update. Woods Hole Oceanographic Institute Tech. Rep. WHOI-96-08, $241 \mathrm{pp}$.

Sloyan, B. M., and S. R. Rintoul, 2001: Circulation, renewal, and modification of Antarctic Mode and Intermediate Water. J. Phys. Oceanogr., 31, 1005-1030, https://doi.org/10.1175/ 1520-0485(2001)031<1005:CRAMOA > 2.0.CO;2.

— L. Talley, T. Chereskin, R. Fine, and J. Holte, 2010: Antarctic Intermediate Water and Subantarctic Mode Water formation in the southeast Pacific: The role of turbulent mixing. J. Phys. Oceanogr., 40, 1558-1574, https://doi.org/10.1175/ 2010JPO4114.1.

Stammerjohn, S. E., D. G. Martinson, R. C. Smith, X. Yuan, and D. Rind, 2008: Trends in Antarctic annual sea ice retreat and advance and their relation to El Niño-Southern Oscillation and Southern Annular Mode variability. J. Geophys. Res., 108, C03S90, https://doi.org/10.1029/2007JC004269.

Swart, N. C., S. T. Gille, J. C. Fyfe, and N. Gillett, 2018: Recent Southern Ocean warming and freshening driven by greenhouse gas emissions and ozone depletion. Nat. Geosci., 11, 836-841, https://doi.org/10.1038/s41561-018-0226-1.

Talley, L. D., G. L. Pickard, W. J. Emery, and J. H. Swift, 2011: Descriptive Physical Oceanography: An Introduction. 6th ed. Elsevier, 560 pp.

Tamsitt, V., L. D. Talley, M. R. Mazloff, and I. Cerovecki, 2016: Zonal variations in the Southern Ocean heat budget. J. Climate, 29, 6563-6579, https://doi.org/10.1175/JCLI-D15-0630.1.

— ters to the surface of the Southern Ocean. Nat. Commun., 8 , 172, https://doi.org/10.1038/s41467-017-00197-0.

Thompson, A. F., and J. B. Sallée, 2012: Jets and topography: Jet transitions and the impact on transport in the Antarctic Circumpolar Current. J. Phys. Oceanogr., 42, 956-972, https:// doi.org/10.1175/JPO-D-11-0135.1.

Tsukernik, M., and A. H. Lynch, 2013: Atmospheric meridional moisture flux over the Southern Ocean: A story of the Amundsen Sea. J. Climate, 26, 8055-8064, https://doi.org/ 10.1175/JCLI-D-12-00381.1.

van Sebille, E., and Coauthors, 2017: Lagrangian ocean analysis: Fundamentals and practices. Ocean Modell., 121, 49-75, https://doi.org/10.1016/j.ocemod.2017.11.008. 
Walin, G., 1982: On the relation between sea-surface heat flow and thermal circulation in the ocean. Tellus, 34, 187-195, https:// doi.org/10.1111/j.2153-3490.1982.tb01806.x.

Willey, D. A., R. A. Fine, R. E. Sonnerup, J. L. Bullister, W. M. Smethie, and M. J. Warner, 2004: Global oceanic chlorofluorocarbon inventory. Geophys. Res. Lett., 31, L01303, https:// doi.org/10.1029/2003GL018816.

Wong, A. P. S., N. L. Bindoff, and J. A. Church, 1999: Largescale freshening of intermediate waters in the Pacific and
Indian Oceans. Nature, 400, 440-443, https://doi.org/10.1038/ 22733.

Wunsch, C., and P. Heimbach, 2013: Two decades of the Atlantic meridional overturning circulation: Anatomy, variations, extremes, prediction, and overcoming its limitations. J. Climate, 26, 7167-7186, https://doi.org/10.1175/JCLI-D-12-00478.1.

Yuan, X., and E. Yonekura, 2011: Decadal variability in the Southern Hemisphere. J. Geophys. Res., 116, D19115, https:// doi.org/10.1029/2011JD015673. 